\title{
تحليل تطور الفكر القومي العنصري في المانيا
}

\section{$(19 \leq 0-19 r \cdot)$}

\author{
نزيار نهمان عباله' كاروان صالخ وميسى

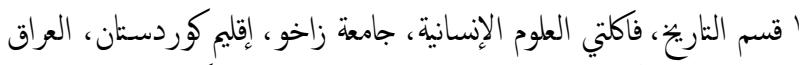

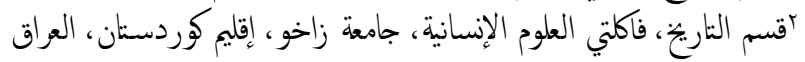

نمى الشعور القوي في أوربا بشكل عام وفي المانيا بشكل خاص في النصف الثاني من القرين التاسع عشر والعثرين وأدى نمو هذا الشعور بدوره إلى بروز وتنامي عاطفة أكثر

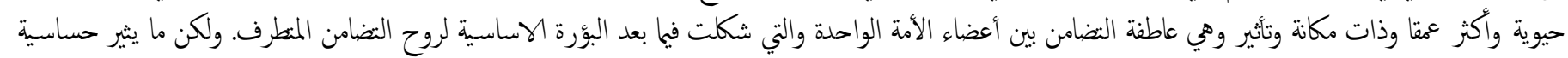

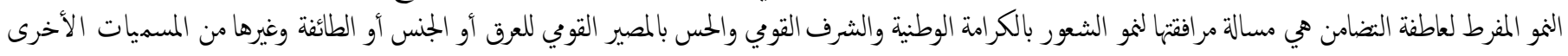

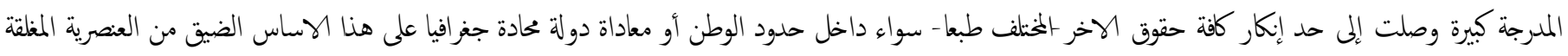

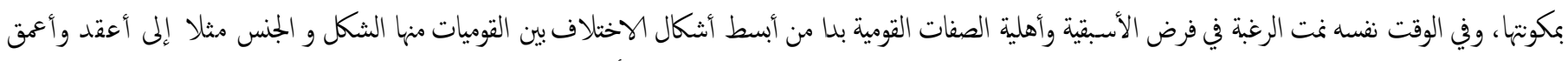

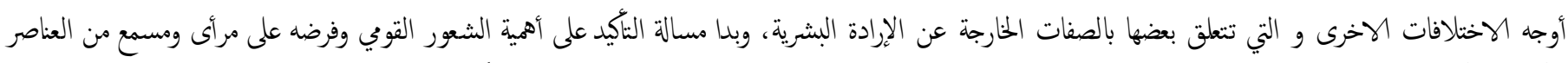

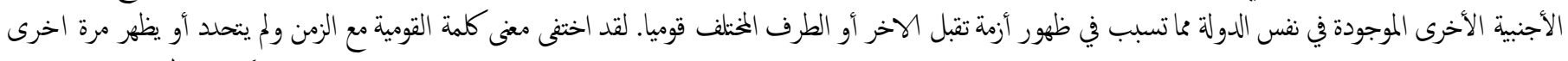

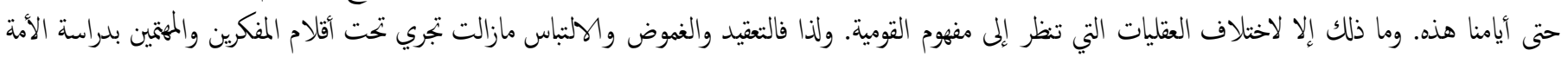
والعطفة القومية.

مفاتيح الكلمات: التاريخ، النطرف، المانيا النازية، ملارس الفكر القوي، الفكر القوي

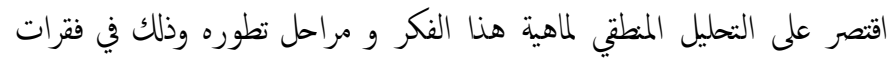

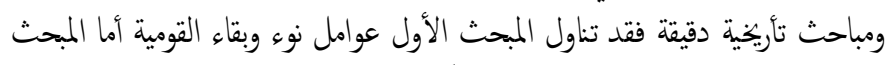

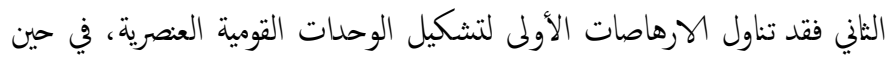

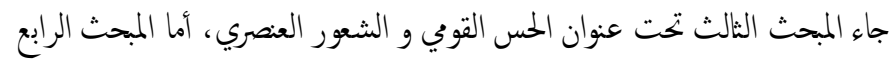

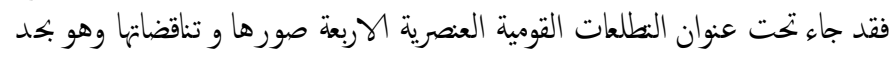

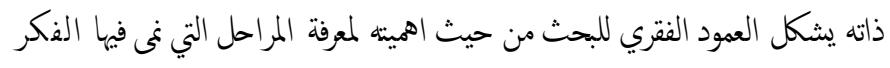

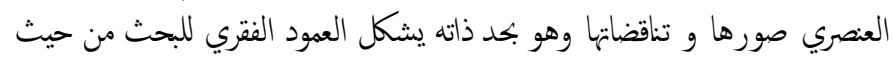

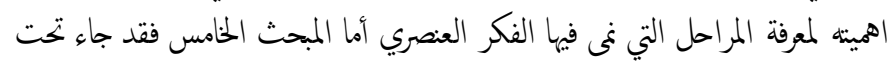

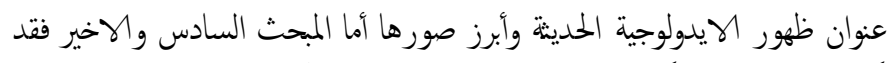

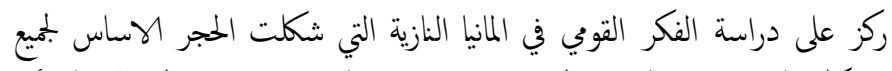

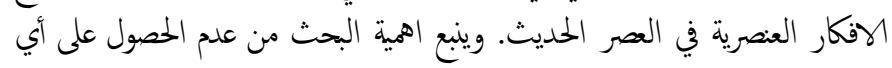

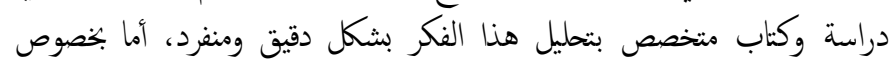

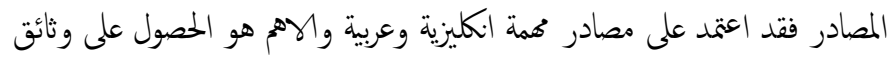

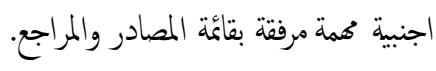

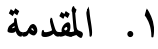

عرف عن تاريخ القرن الثاسع عشر والقرن العشرين بكونه مطبوعاً بطابع الحركات

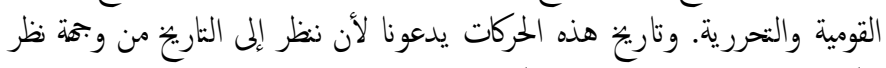

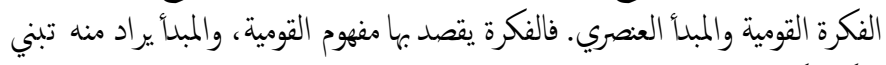

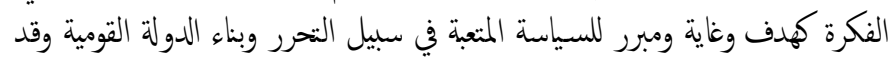

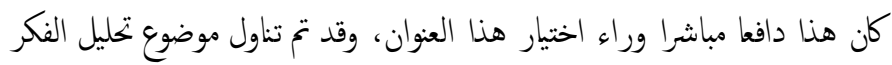

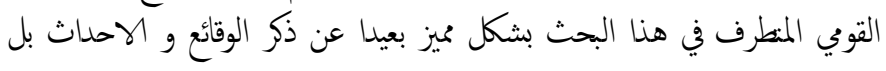

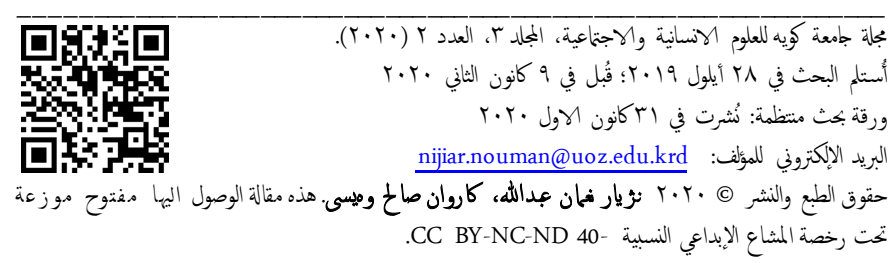




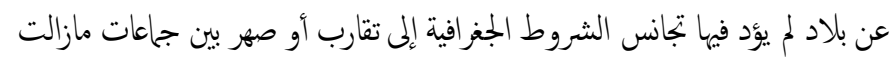

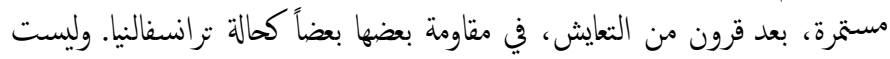

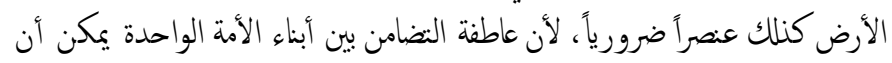

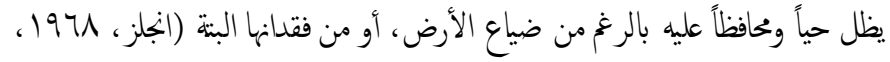

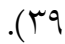

العرق: أن التشابه بين الصفات الجسدية، من حيث الهيكل الجسماني وشكل

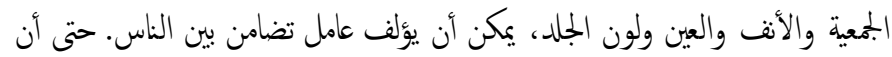

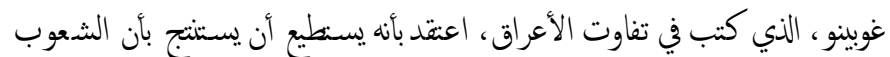

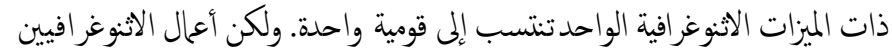

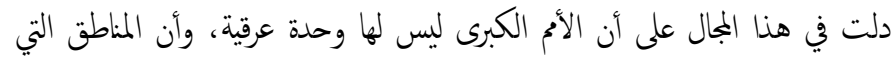

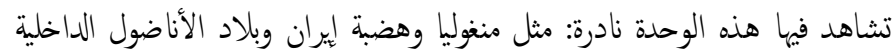

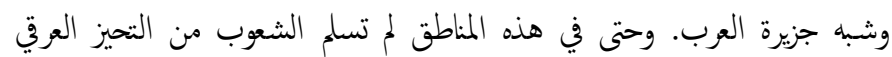

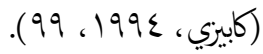

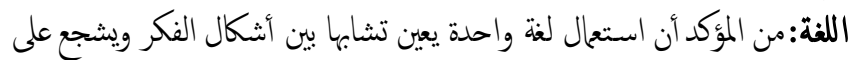

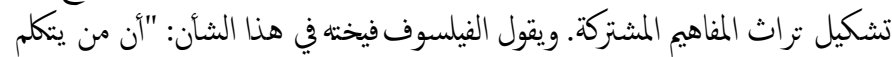

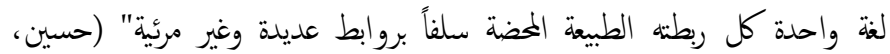

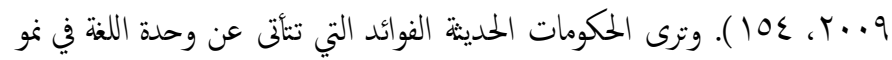

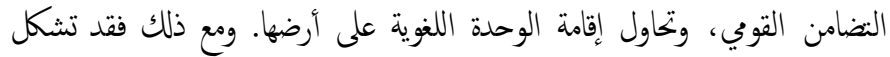

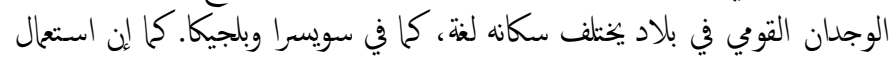

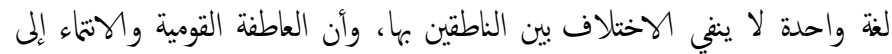

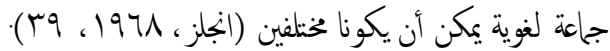

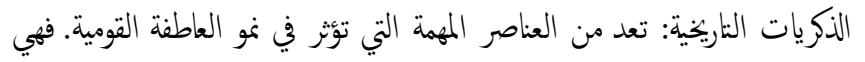

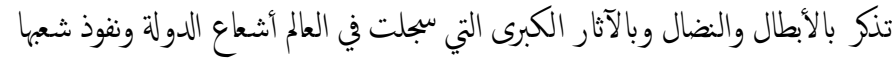

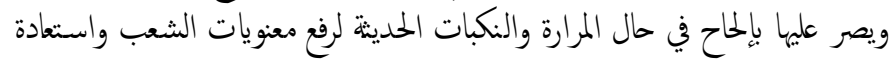

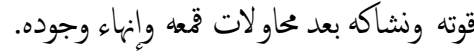

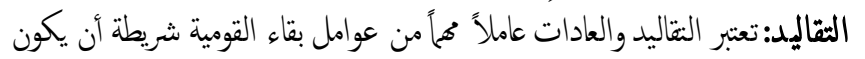

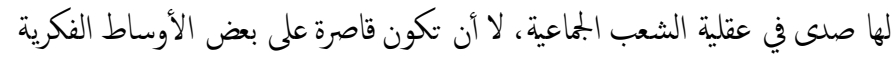

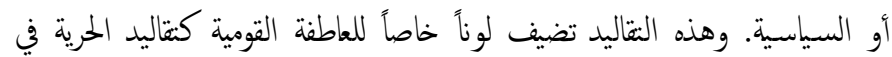

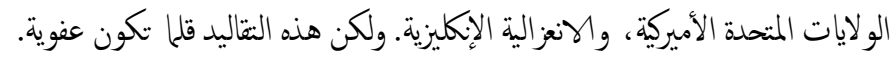

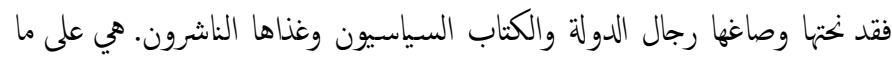

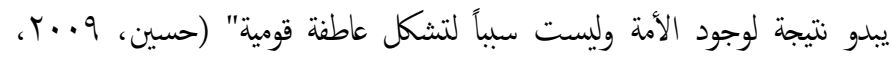

.) (10

الحضارة الفكرية: أن نشأة الشعور القوي تفترض وجود حضارة. فنمو الأدب

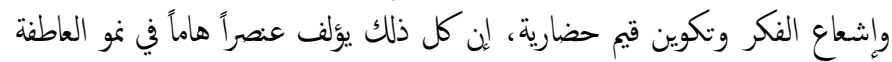

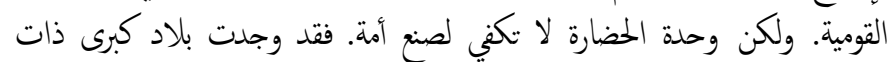

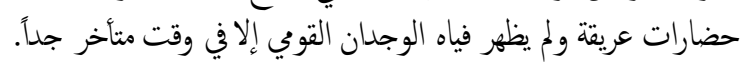

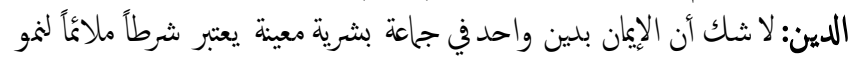

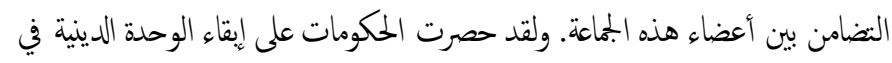

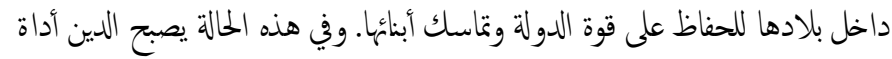

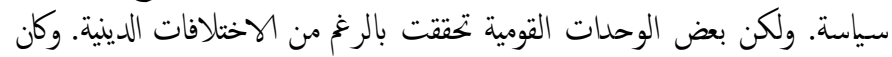

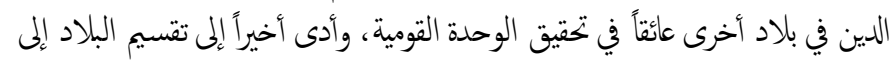

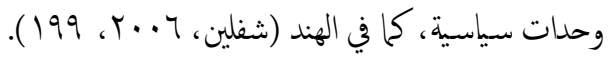

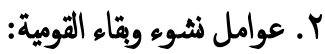

يرجع أصل كلمة القومية إلى القوم وتعني الأمة، أما تفسير تطور الفكر القومي في

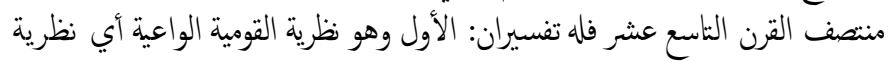
المفكرين الفرنسيين؛ والثاني نظرية القومية اللاواعية وتعني نظرية الفلاسفة الألمان الفان.

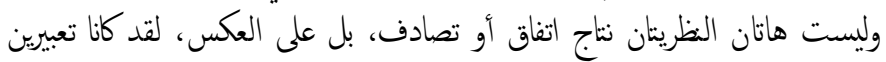

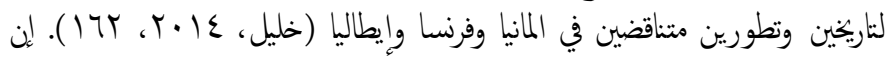

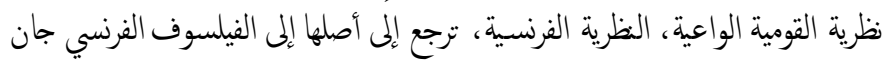

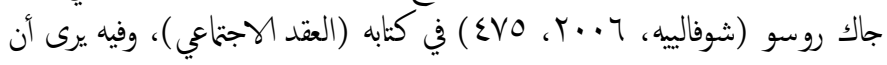

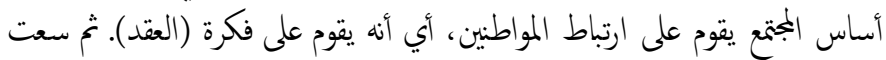

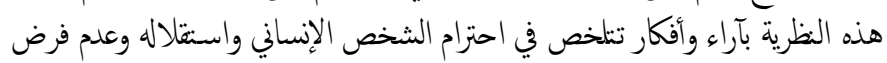

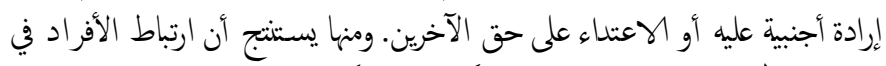

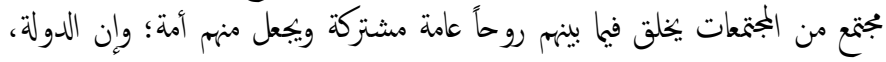

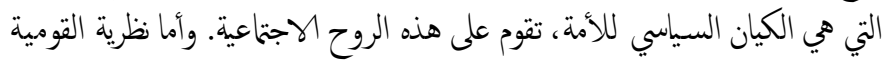

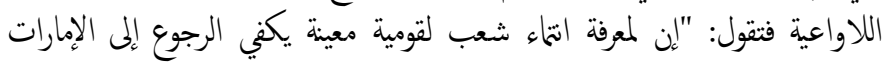

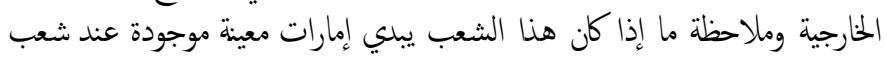

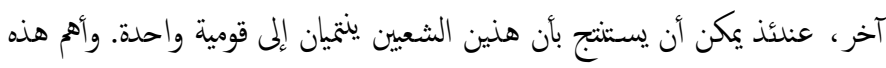

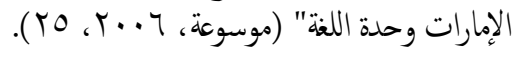

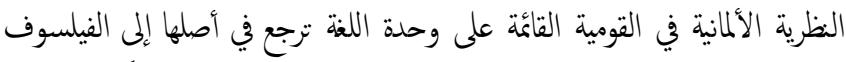

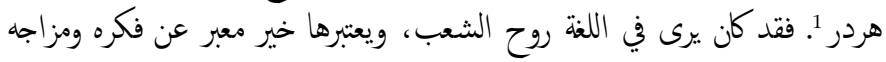

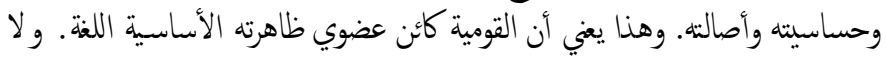

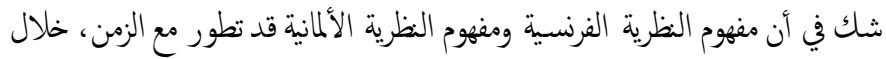

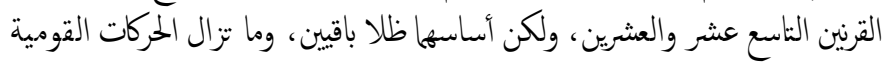

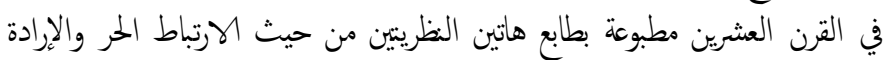

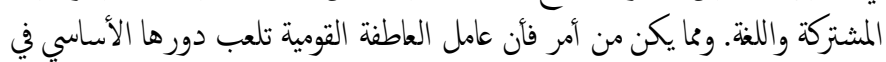

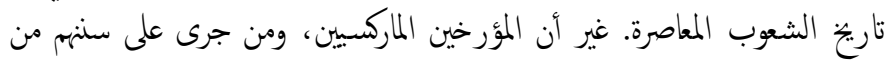

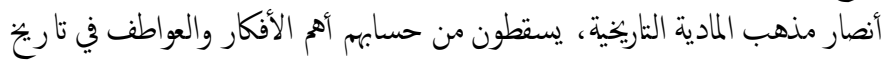

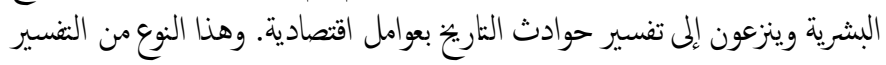

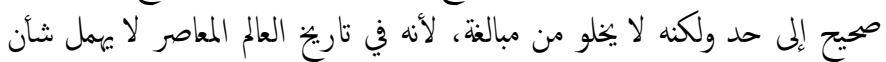

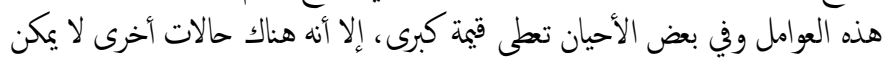

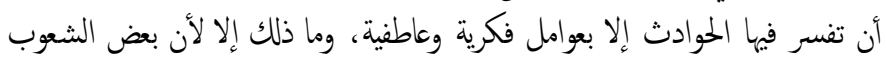

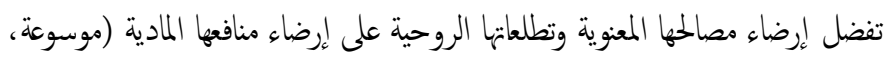

. ( 19 ، r...

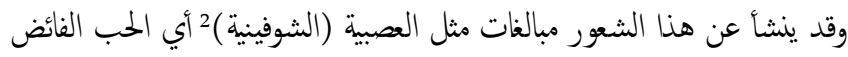

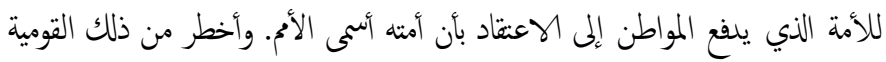

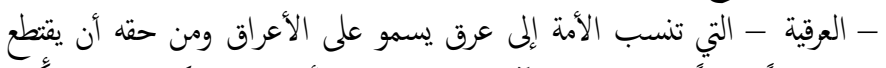

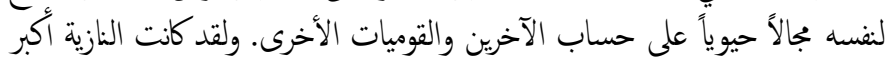

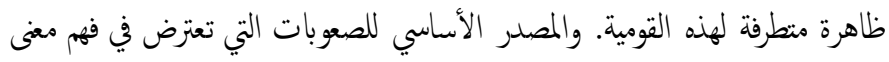

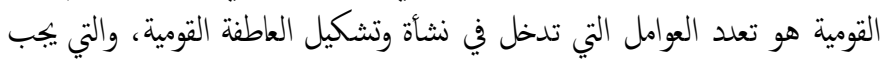

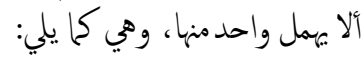

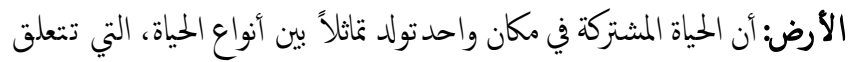

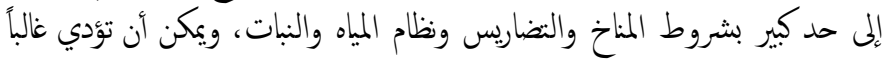

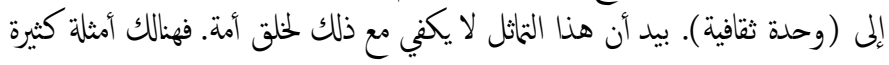




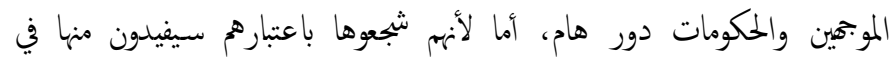

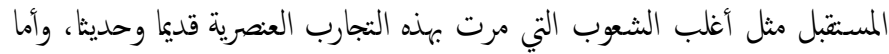

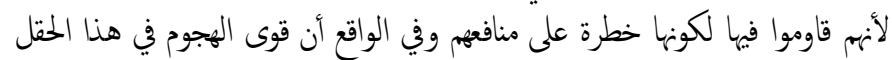

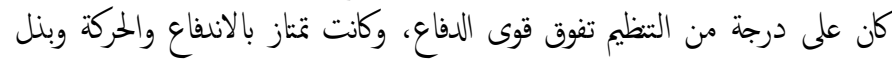

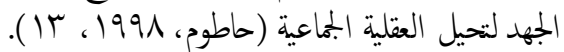

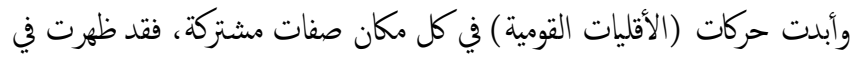

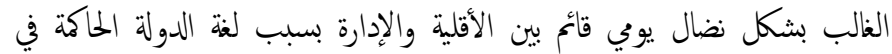

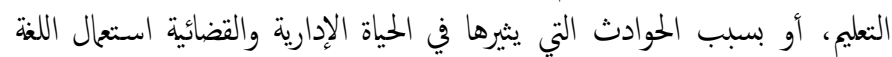

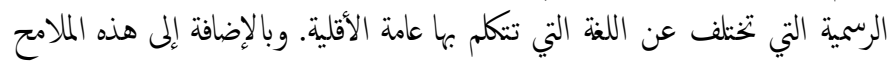

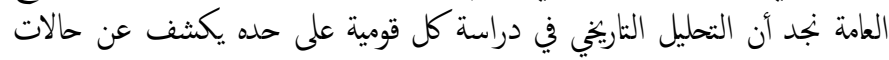

مختلفة.

وفي هذه الحركات أو تلك كان عمل المفكرين حاساً، فقد أحيوا الذكريات التاريخية

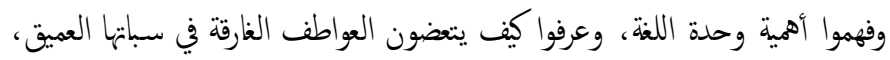

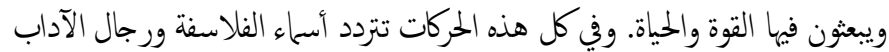

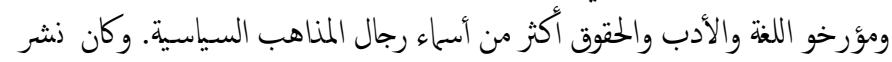

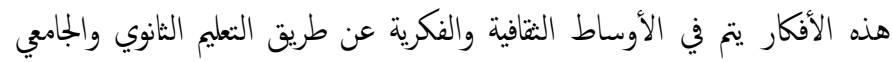

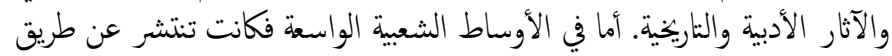

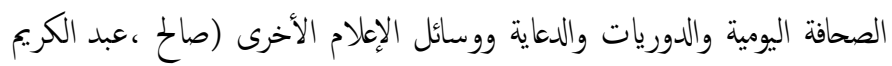

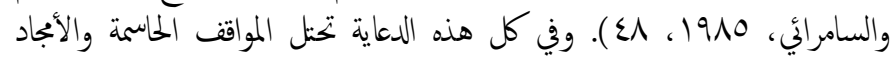
القومية والتقاليد الشعبية المكان الأسمى.

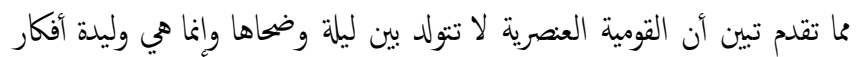

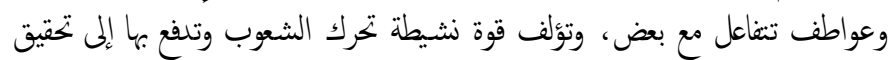

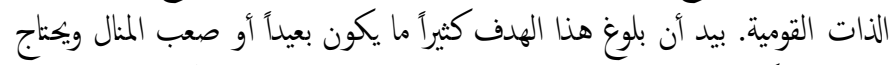

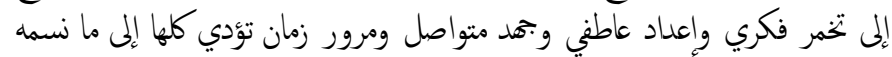

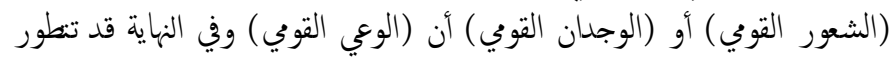

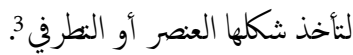

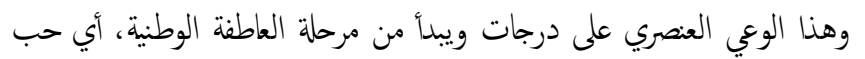

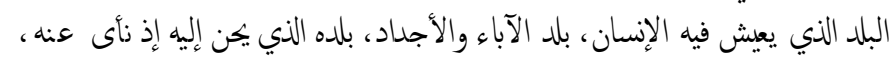

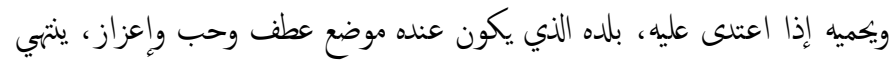

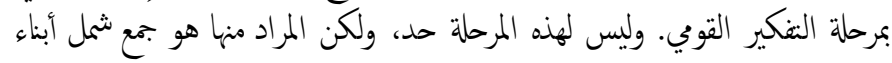

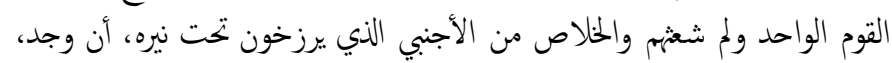

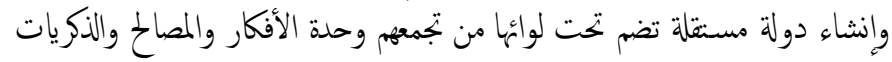

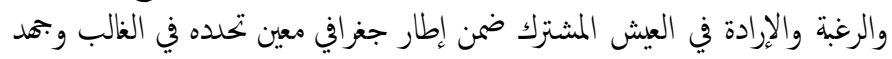
المسنطاع اللغة القومية.

\section{ع. الحس القومي والثعور العنصري:}

أن البحث في الشعور القوي ينطلب البحث في الشعور العنصري أيضاً. إذ يوجد المبا.

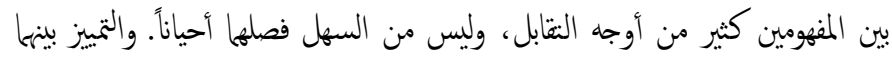

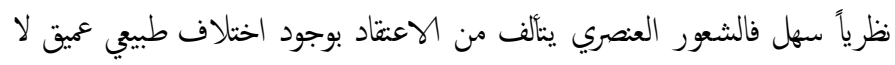

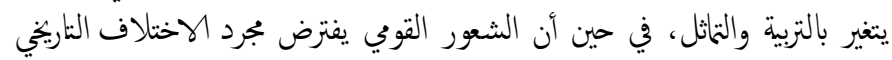

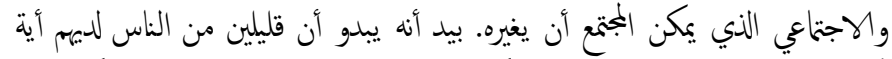

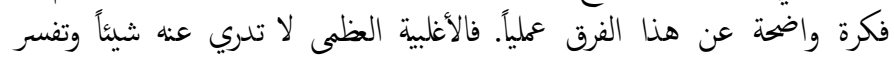

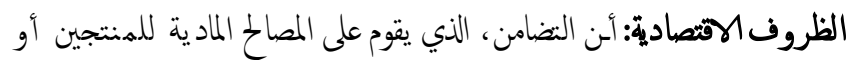

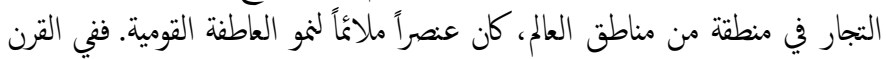

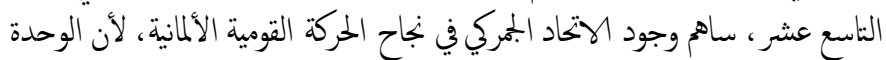

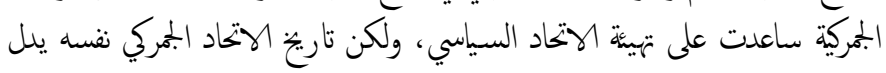

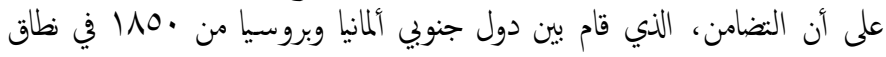

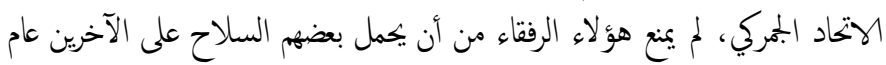
(Tr، 199\&،Craig) 1 1 177

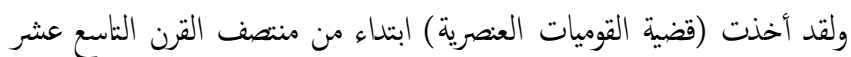

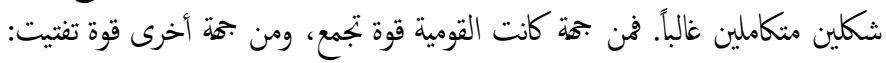

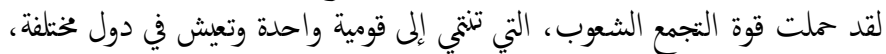

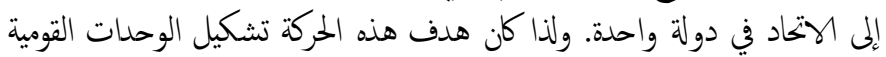

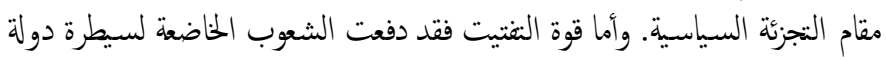

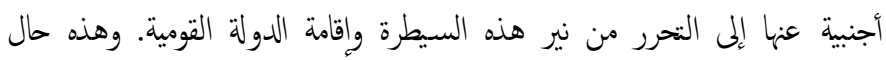

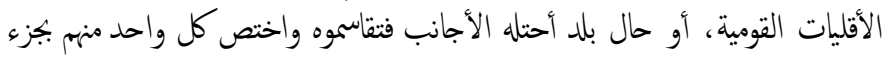

\section{r. الإرهاصات الأولى لتشكيل الوحلات القومية الهنصرية:}

في البدء كان لتشكل الوحلات القومية دور مسيطر في ظهور النزعات القومية

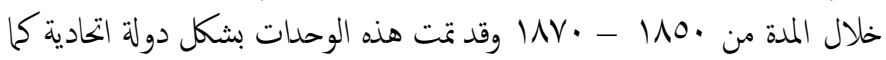

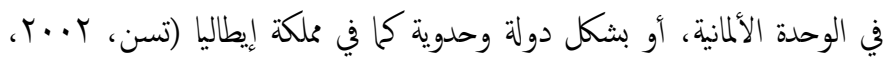
(IIV

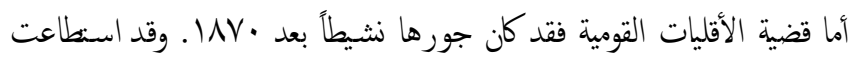

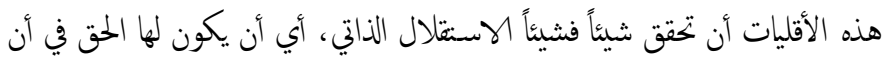

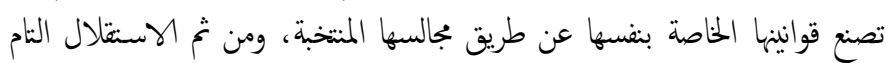

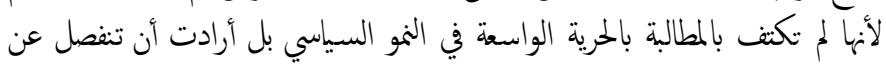

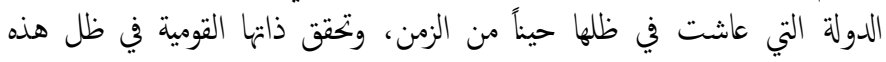
الاستقلال الذي حصلت عليه.

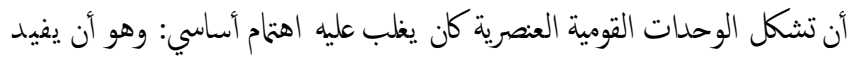

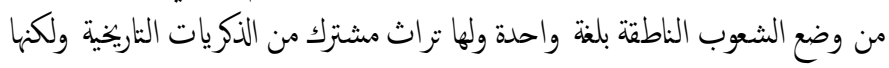

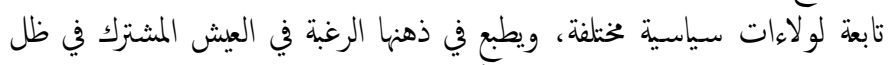

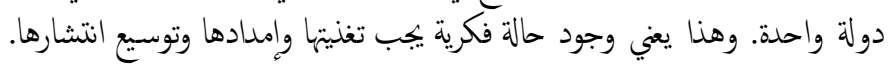

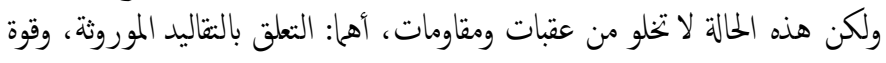

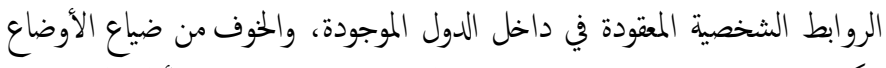

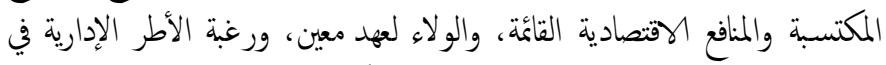

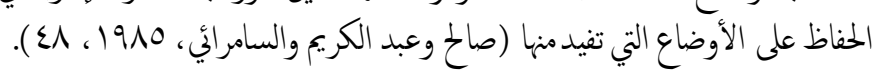

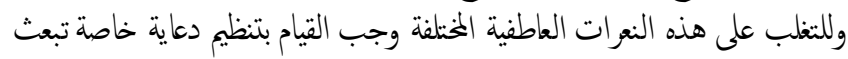

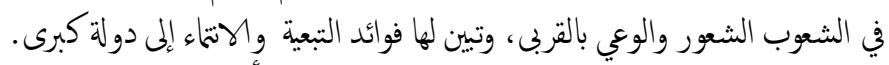

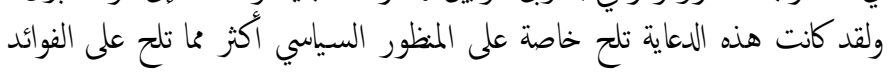

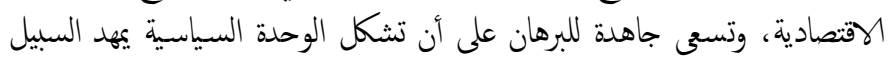
إلى القوة. ولكن النشاط الذي قام به بصض رجال الفكر لم يكن وحلده كفياً ليقطي لهذه

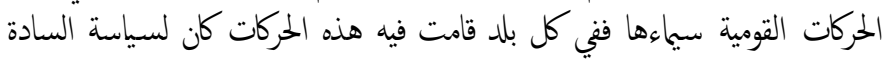


اجتاعي بين الطبقات المتقابلة في الأجناس المختلفة لابد أن يثير التنمر العنصري

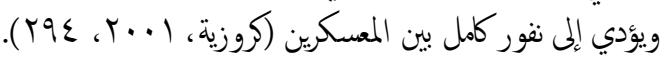

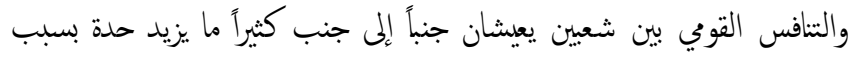

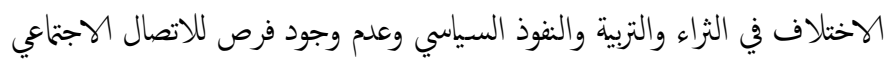

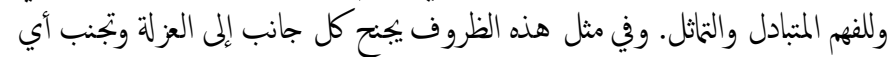

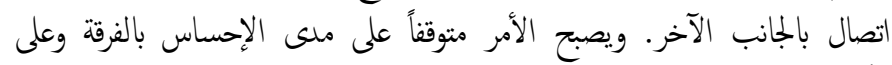

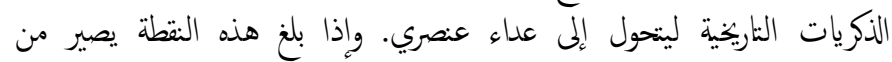

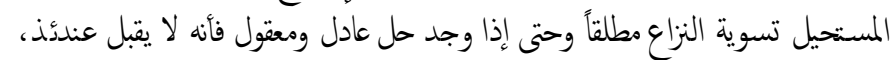

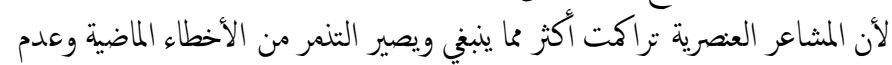

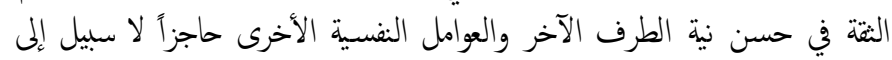

التغلب عليه 5 والتحالف الحديث بين النزعة القومية والعنصرية له أثر غريب في الحيلولة دون

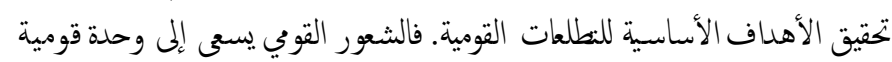

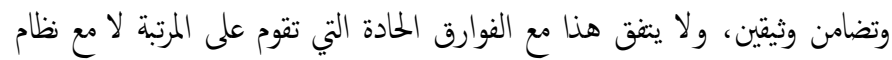

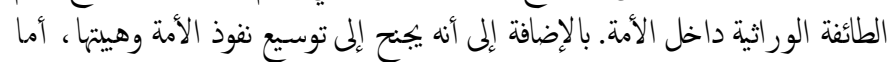

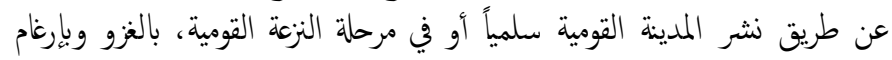

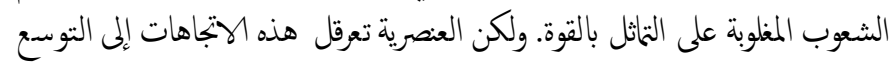

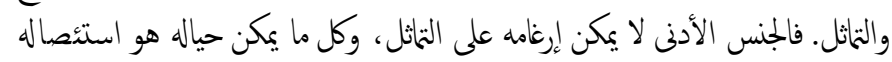

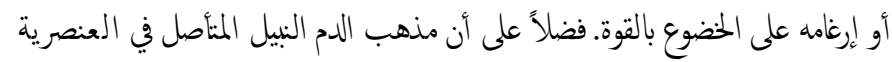

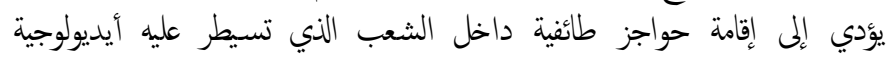
العنصرية وبنلك يعمل على تلدير الوحدة والتضامن القوميين.

\section{0. الثطلعات القومية المنصرية الأربة صورها وثاقضاتها:}

كان المجتع في القرن 17 يقوم إلى حدكير على جاعات تربطها رابطة الدم الحقيقية

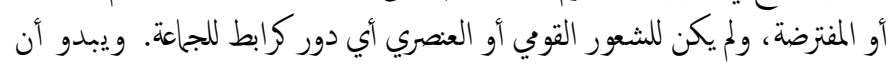

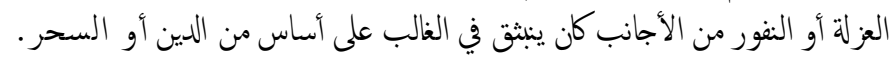

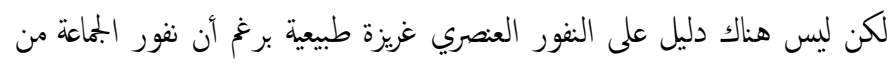

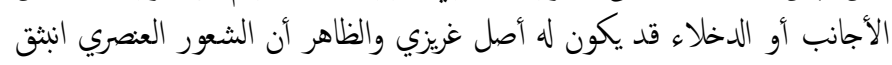

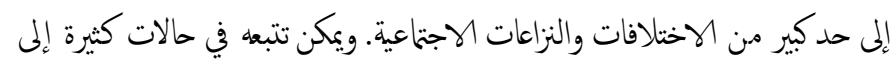

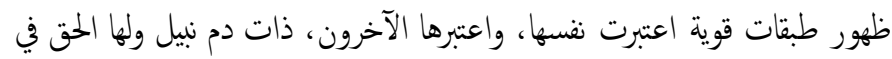
مركز ممتاز ينطوي على العزلة كطائفة 6.

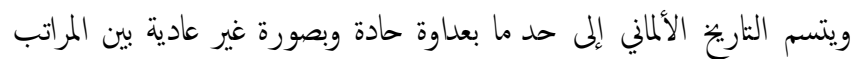

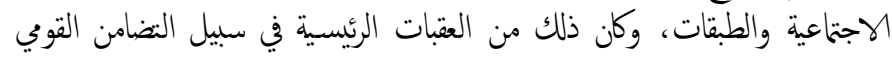

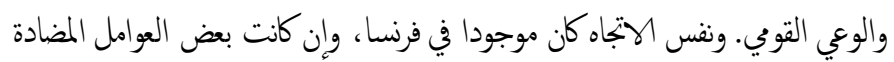

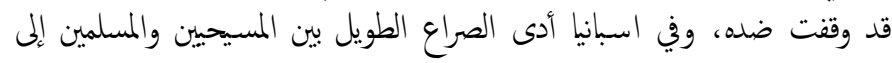

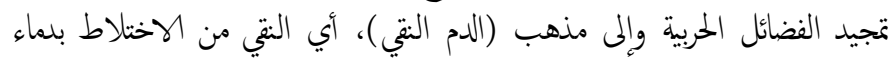

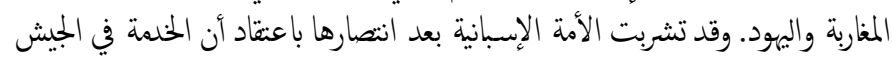

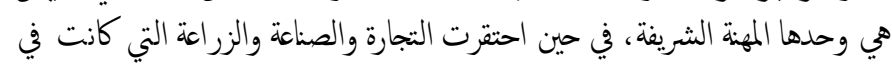

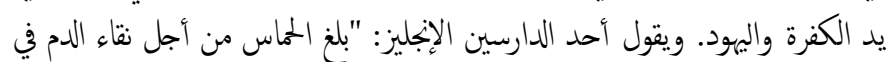

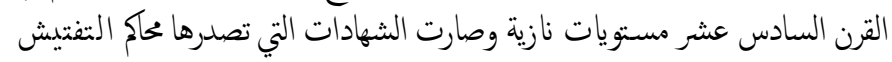

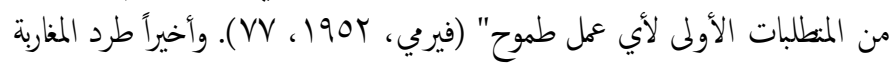

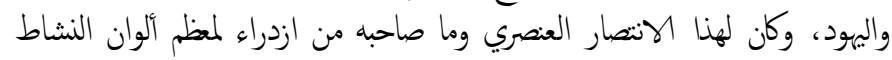

الاختلافات القومية باستمرار على أنها اختلافات عنصرية. بل أن قوة العنصرية كيرة

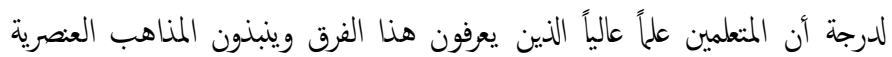

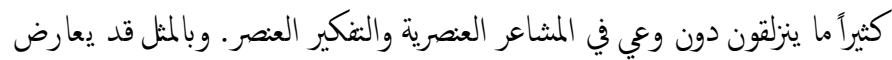

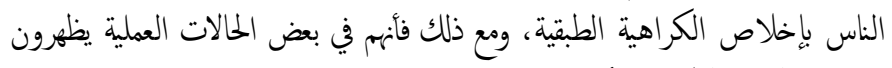

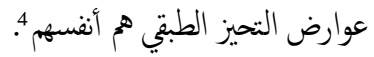

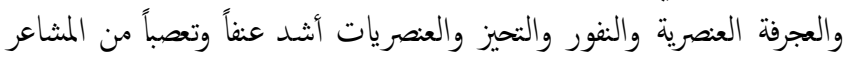

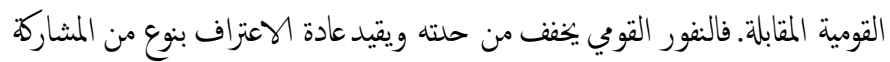

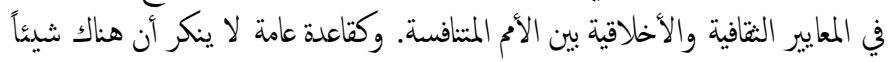

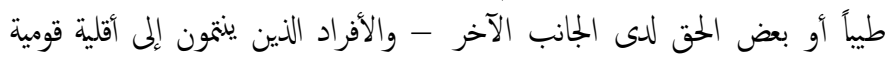

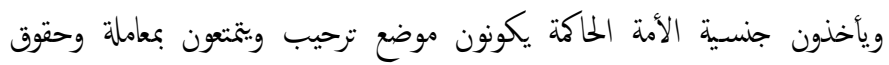

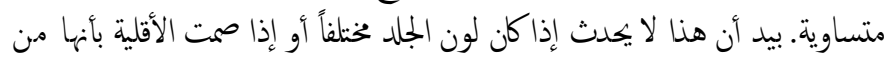

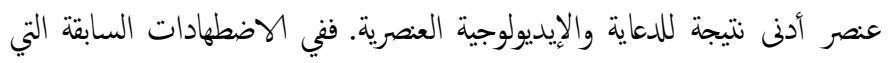

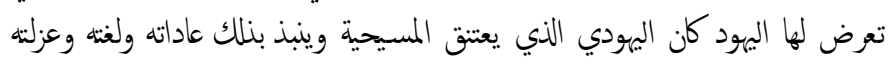

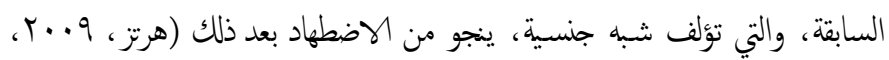

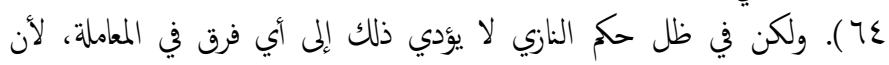

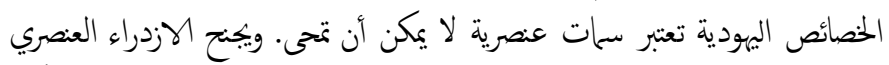

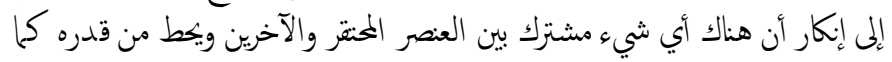

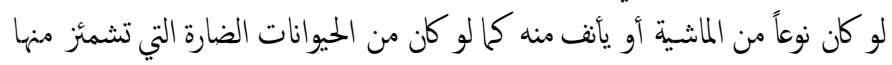
والاعثقاد العنف لدى شخص ما بنفوق عنصراً من المناهب التي تجنح لأن تصير

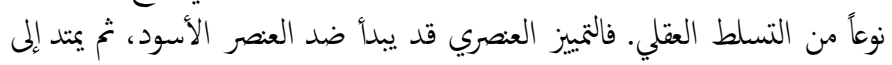

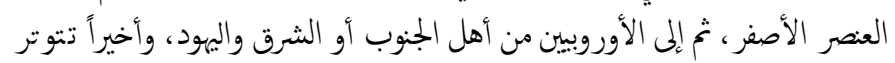

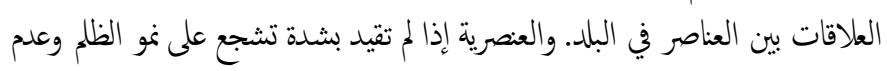

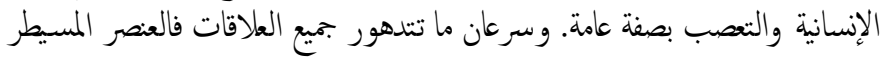

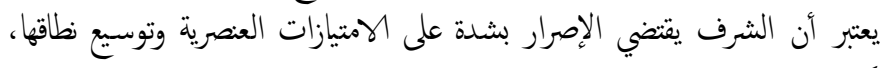

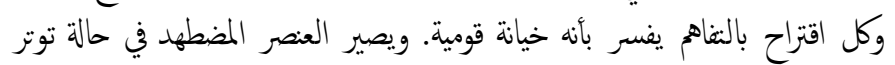

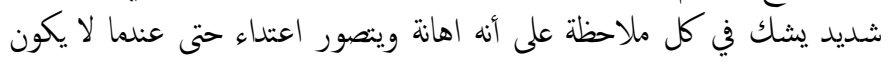

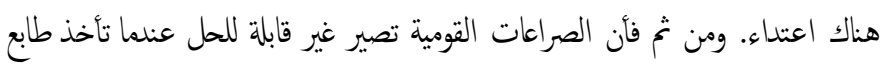

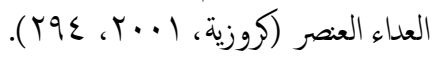

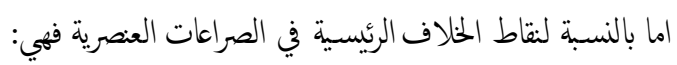

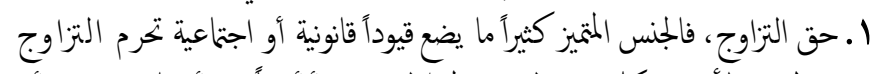

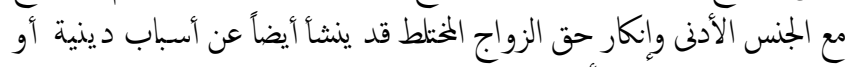

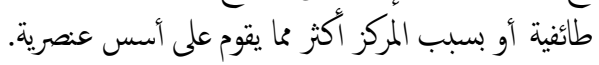

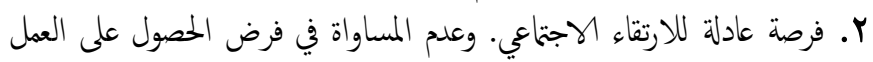

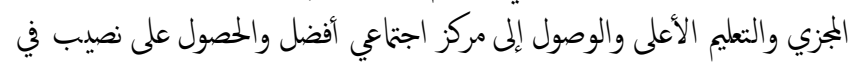

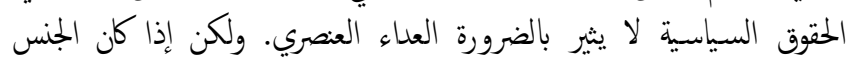

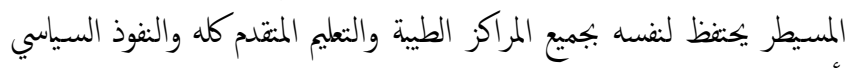

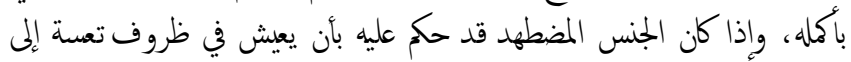
الأبد بدون أمل في التحسن، يكون من العسير ألا تعتبر هذه المعاملة احتقارً عنصرياً.

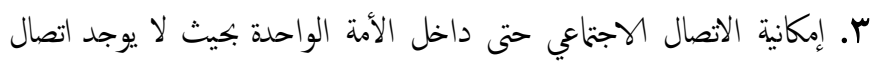

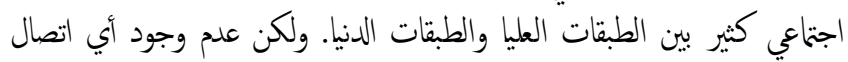




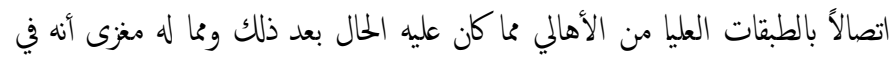

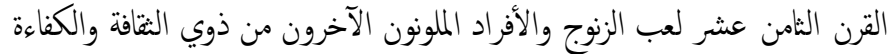

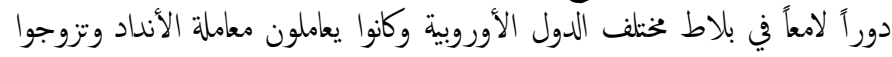

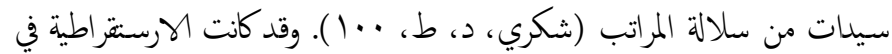

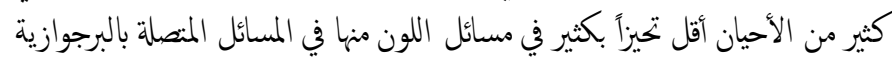

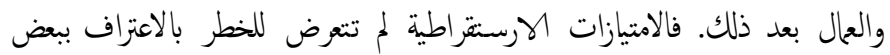

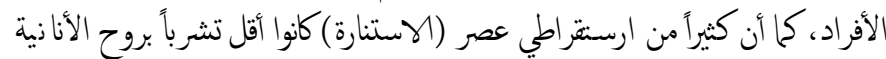

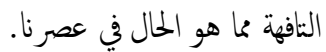

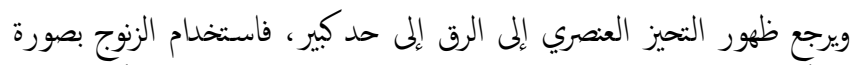

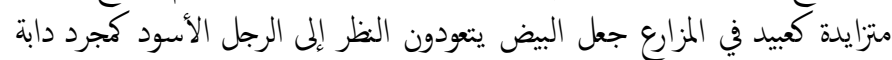

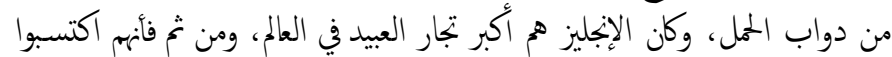

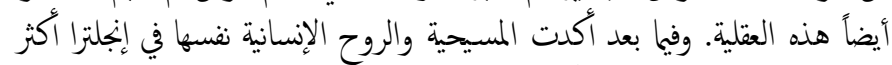

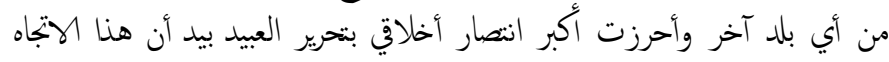

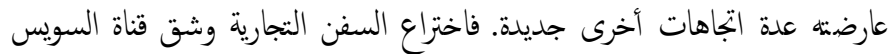

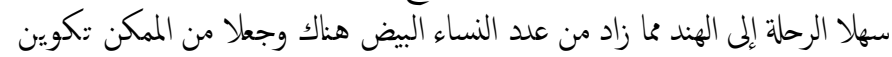

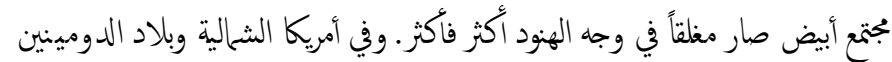

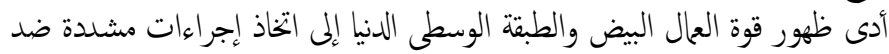

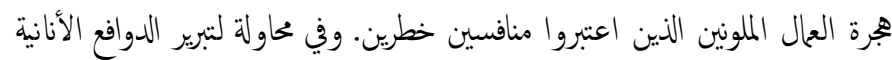

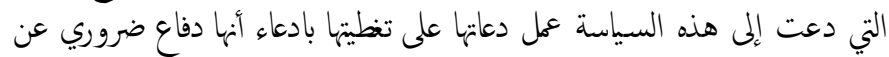

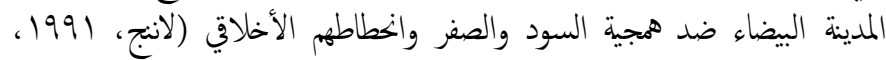

ص صT7).

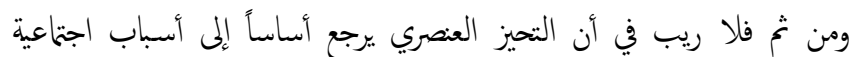

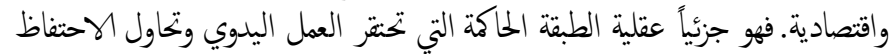

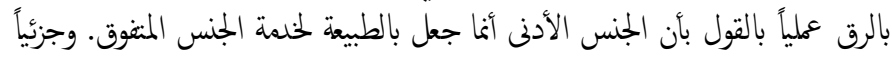

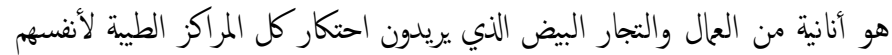

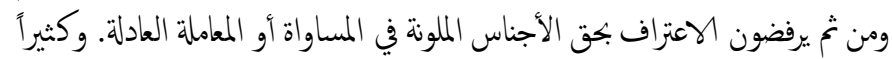

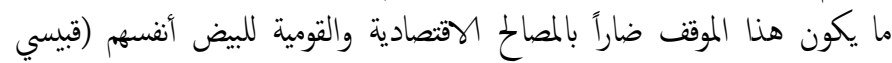

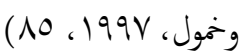

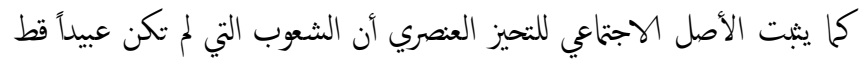

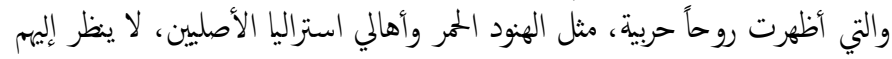

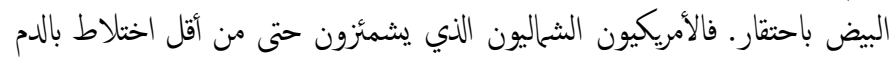

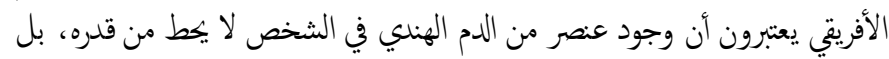

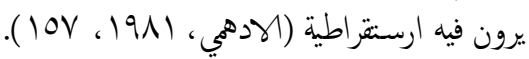

\section{7. ظهور الأيديولوجية المنصرية الحدية:}

أن تكوين الأمة الحديثة يتوقف على التغلب على الانقسامات الاجتماعية التي تقوم

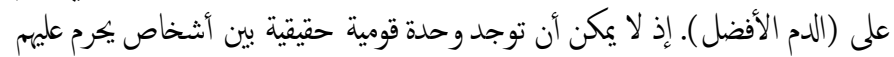

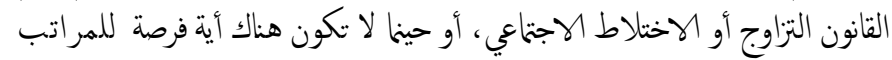

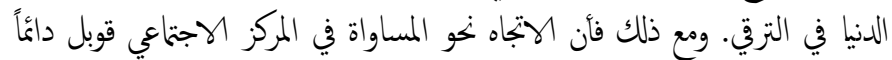

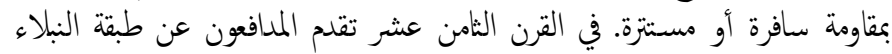

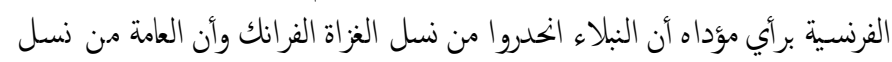

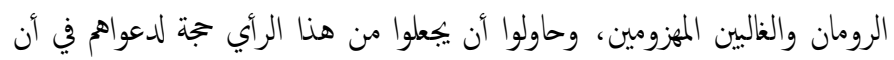

الاقتصادي وعقلية حربية بصفة عامة أثر كير في انهيار قوة إسبانيا ورخائها.

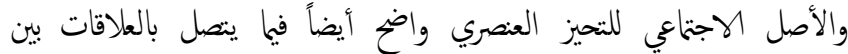

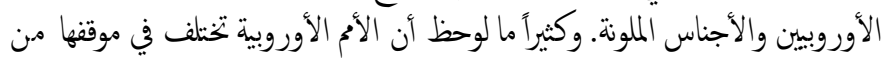

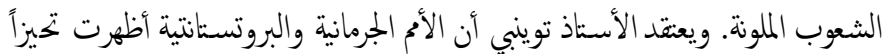

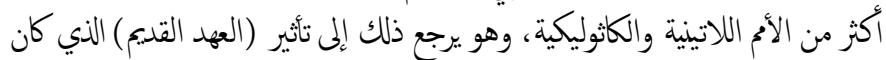

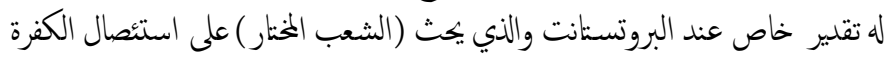

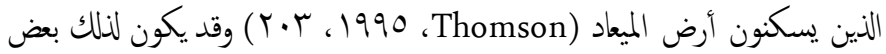

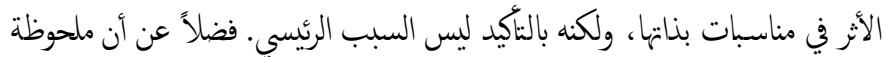

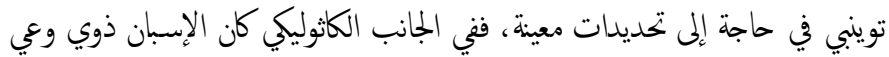

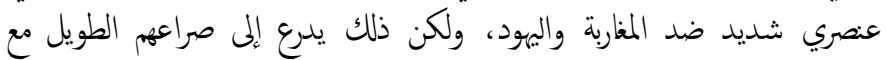

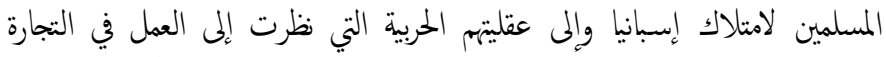

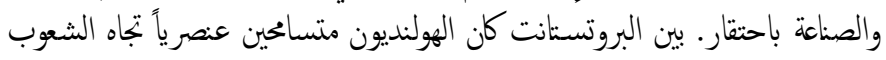

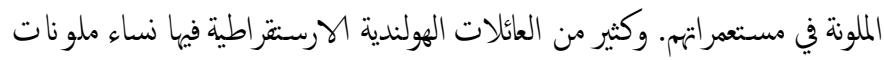

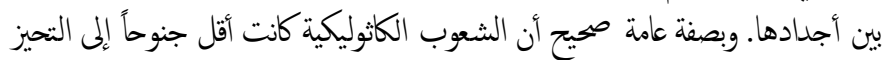

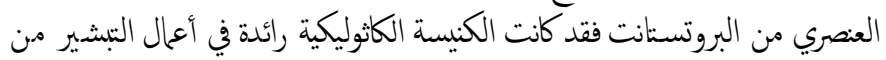

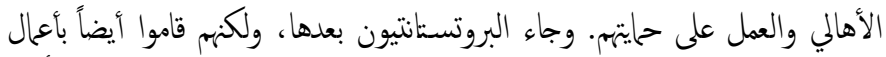

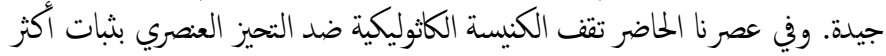

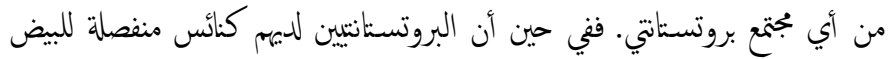

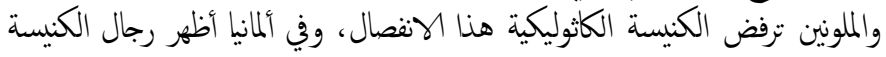

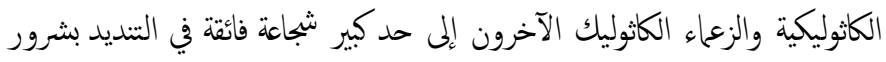

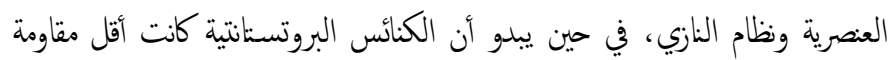

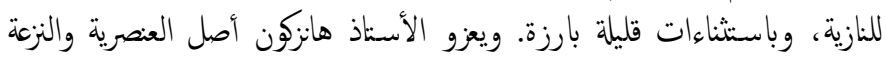

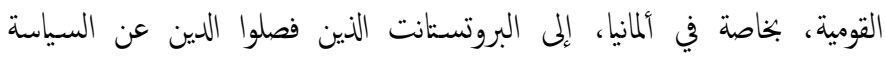
(Thomson)

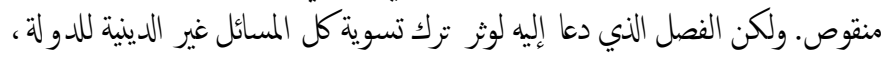

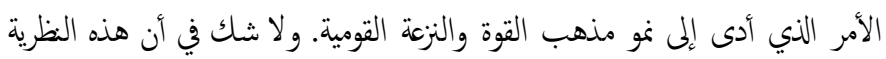

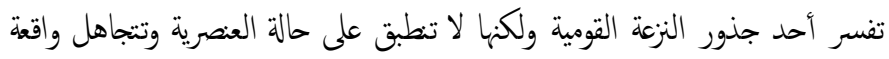

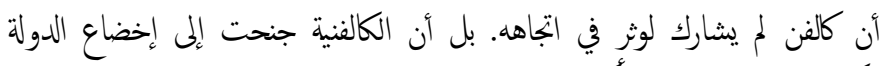

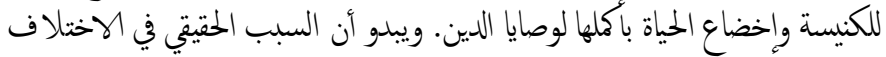

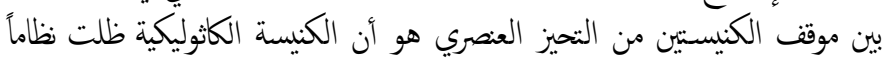

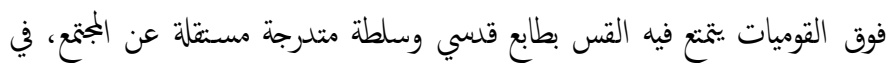

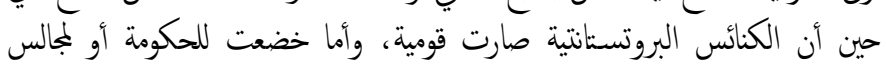

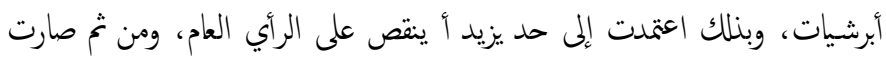
عرضة لعدوى التحيزات السائدة.

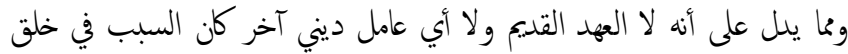

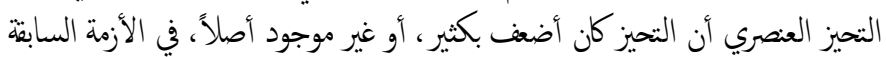

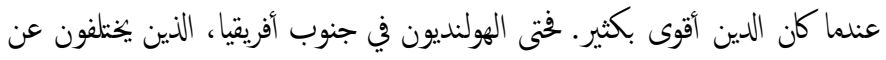

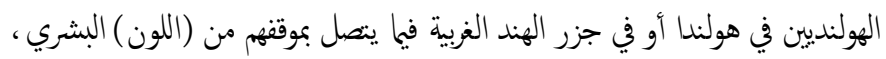

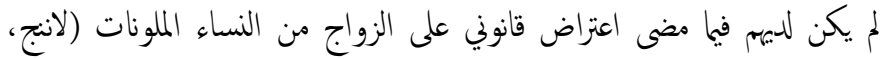

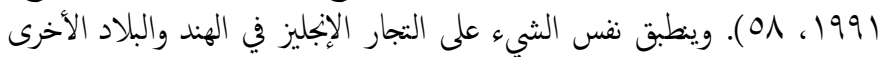

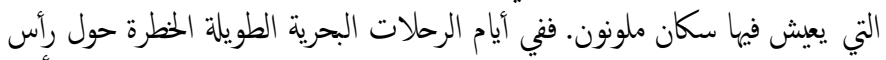

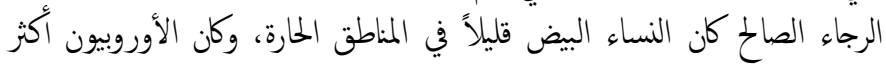


للاضطهادات التي تعرضوا لها، وقد أتاح لم هنا الاتتشار تجارباً واتصالات عديدة

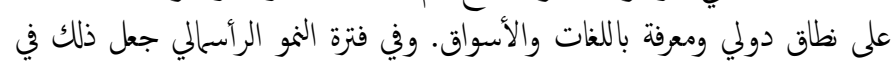

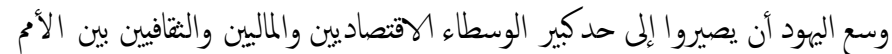

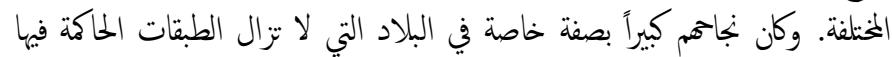

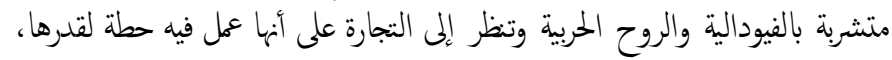

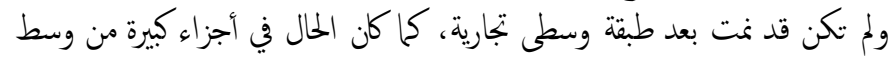

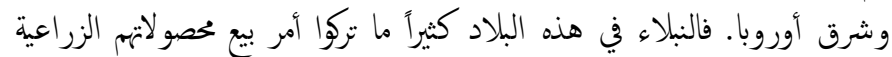

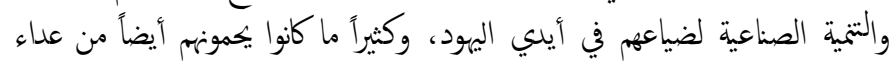

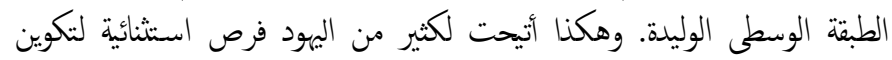

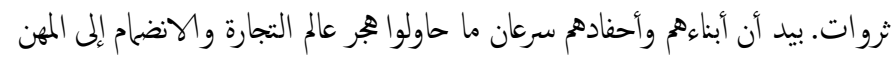

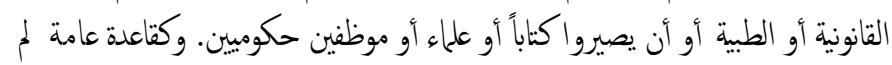

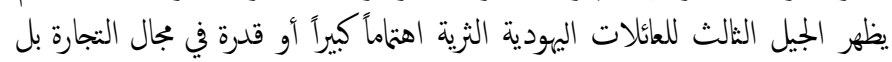

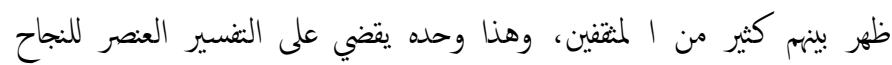

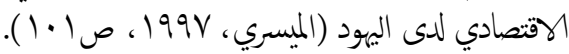

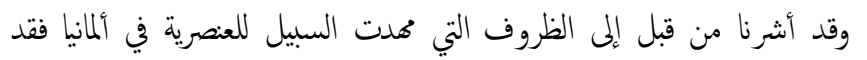

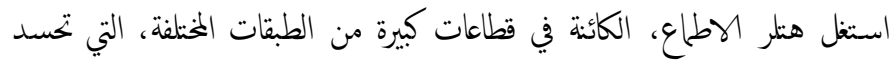

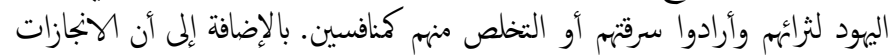

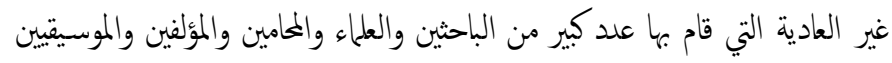

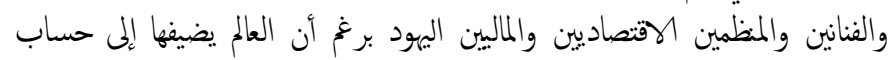

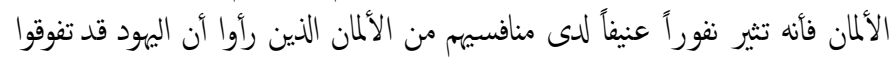

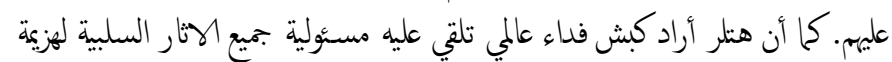

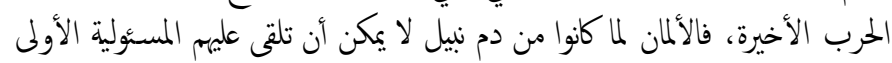

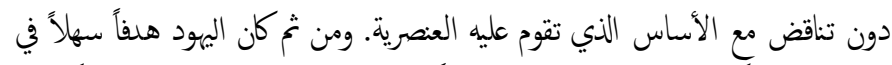

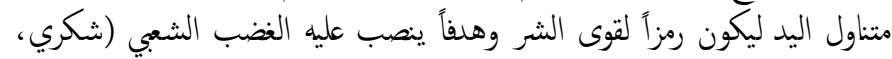

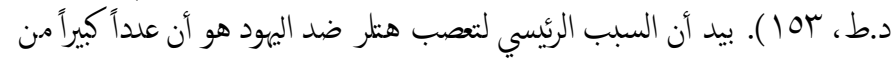

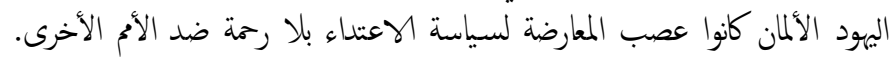

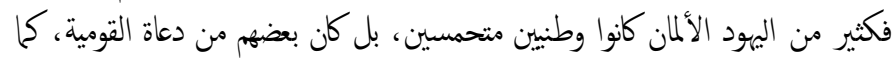

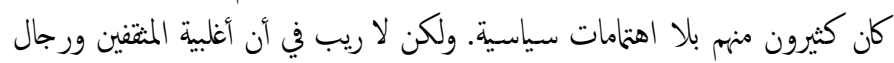

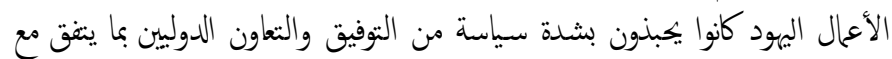

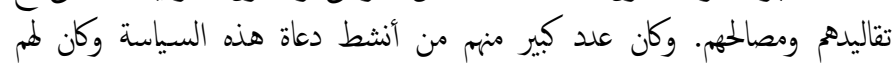

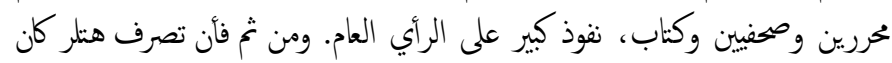

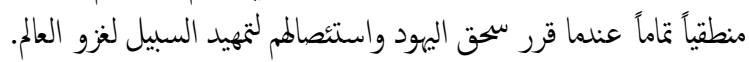

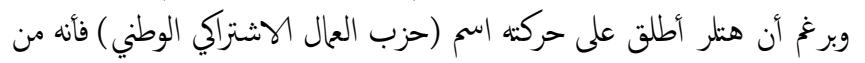

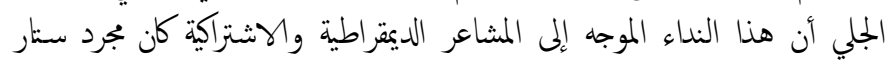

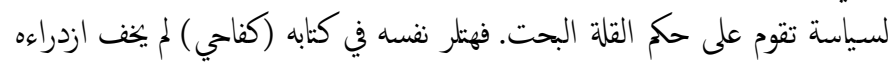

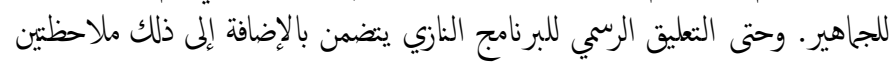

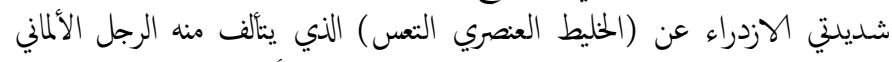

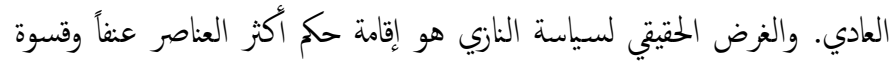

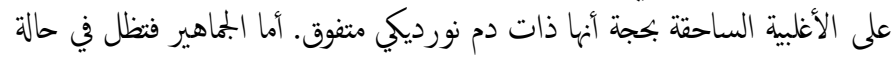

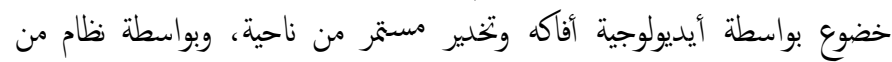

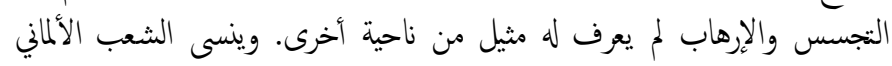
عبوديثه عن طريق الإحساس بالفخر بالانتاء إلى أنبيل الأجناس في الأن الأرض الألمان
يكونوا في مركز المكام. وكانت هذه نقطة البداية في جل طويل حول حول الأصل

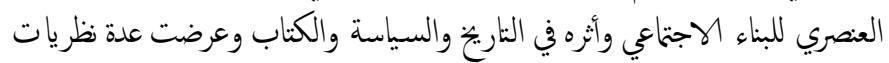

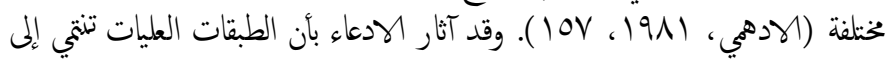

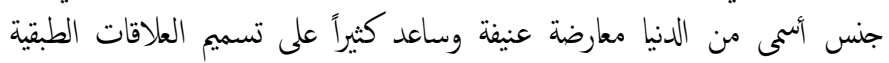

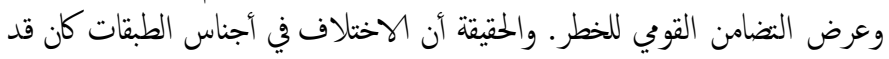

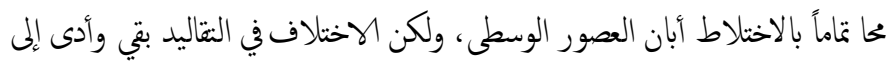

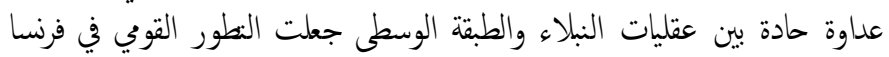

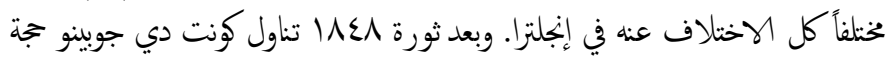

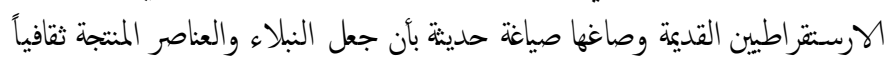

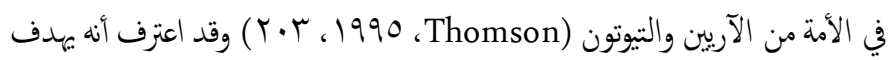

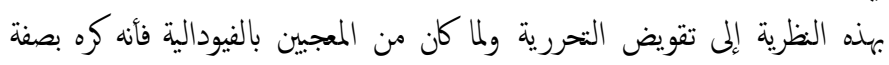

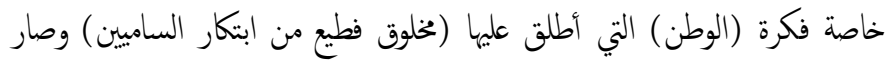

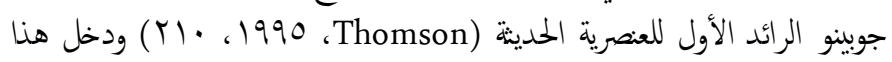

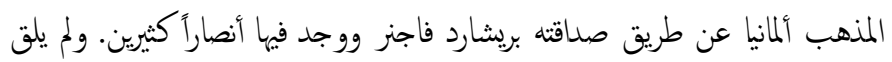

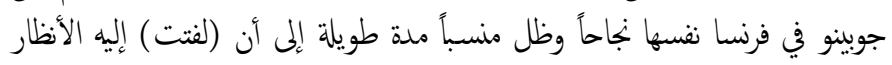
شعبيته في ألمانيا.

فقد دعا فاشيه دي لا بوج وبعض الكتاب الآخرين إلى ظرية أن الطبقات العليا

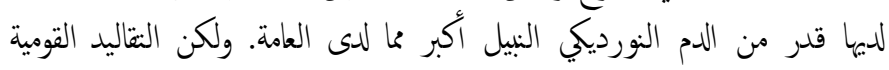

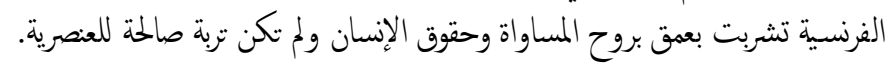

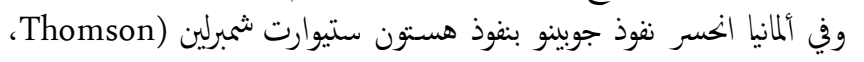

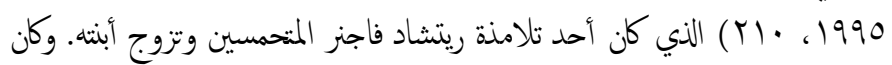

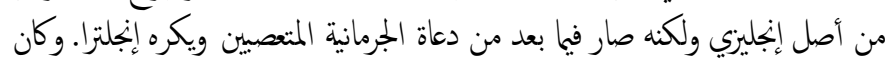

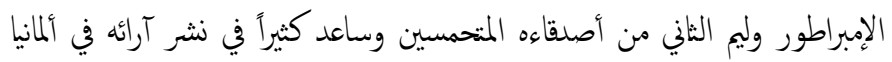

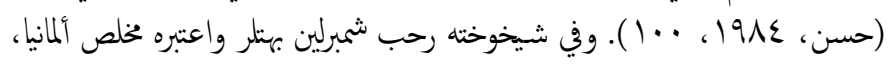

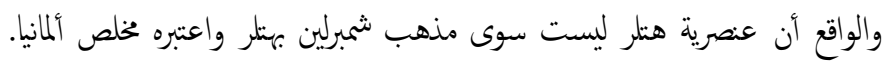

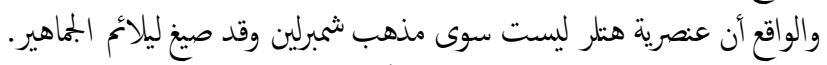

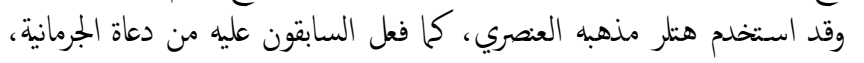

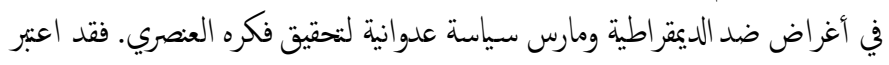

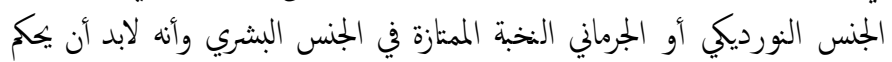

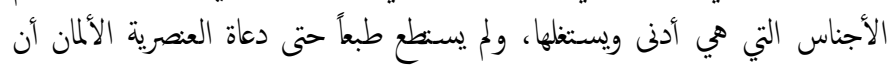

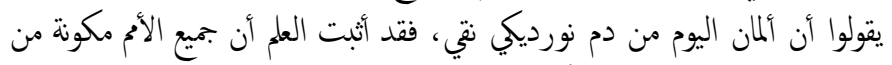

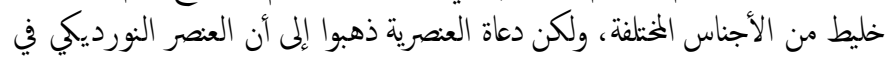

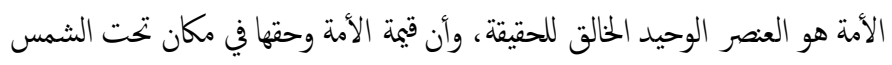

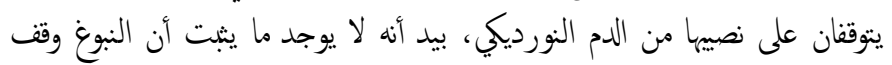

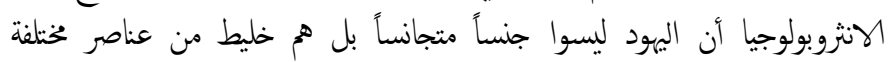

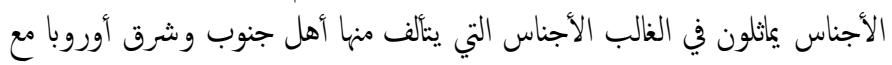

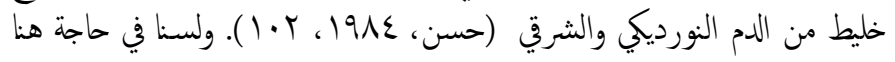

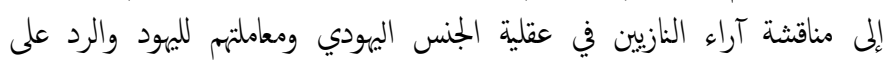

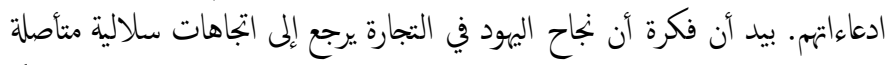

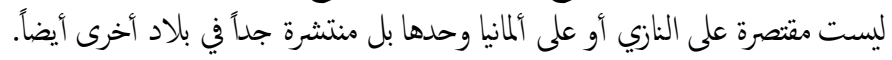

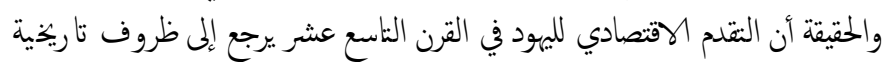
واجتاعية ولا علاقة له بالجنس، فن المن الأسباب الكبرى لإن لانتشار اليهود نتيجة 


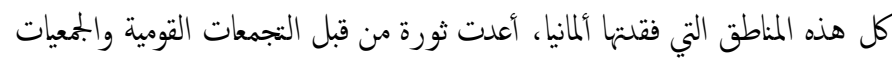

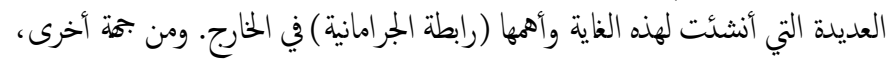

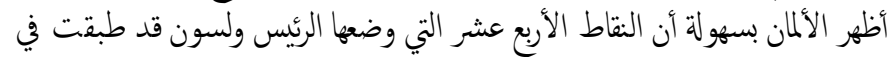

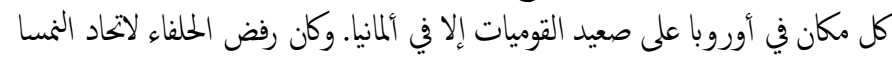

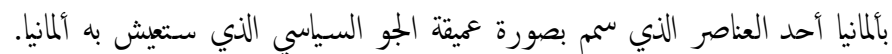

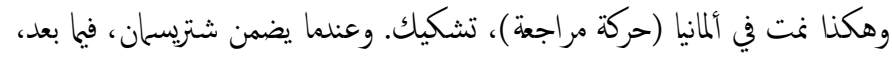

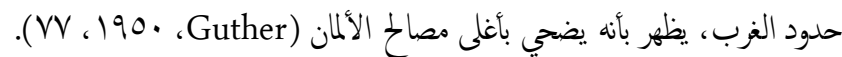

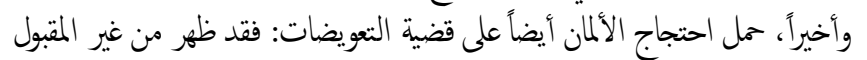

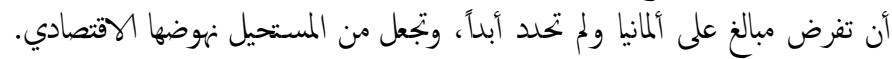

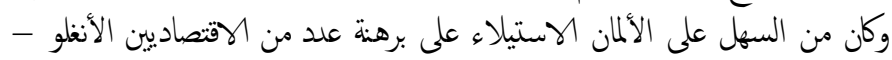

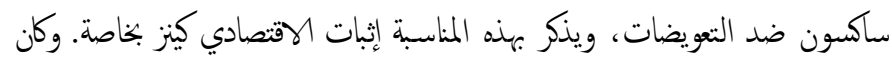

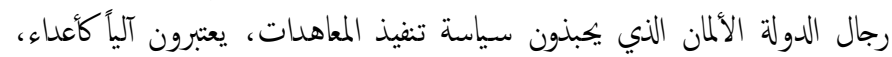

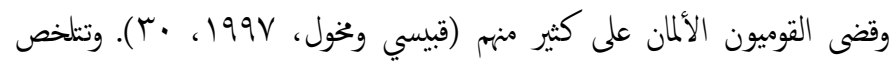

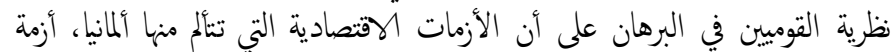

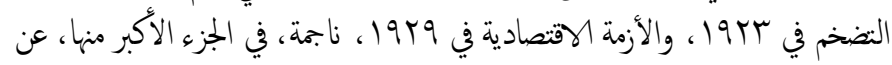

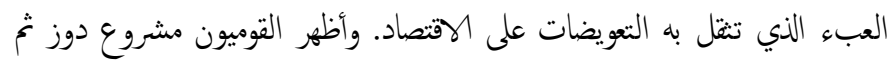

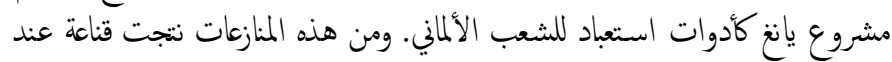

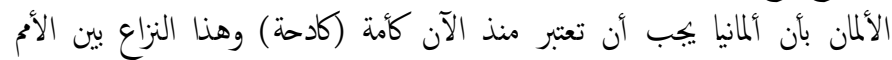

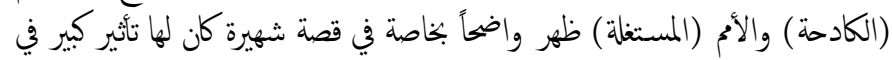

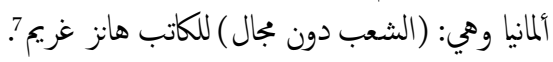

\section{r. النقد الني وجه لمؤسسات المجهورية.}

ولم تكن معاهدة فرساي وحدها سباً في نمو القومية في ألمانيا لأن النظام السياسي إنهاي

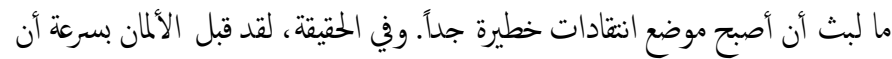

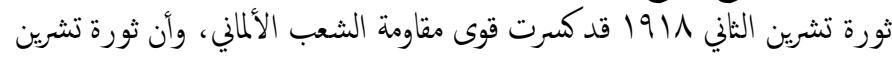

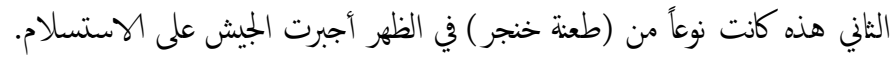

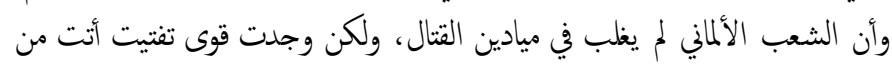

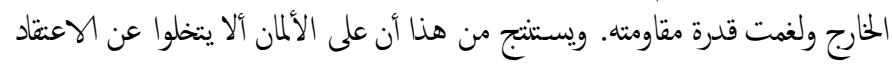

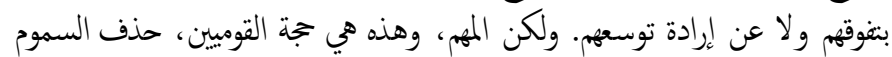

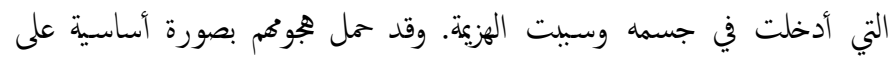

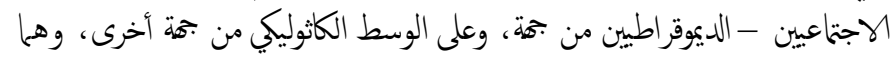

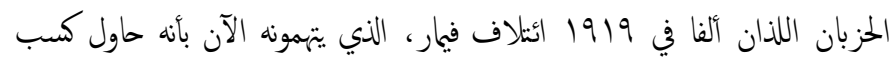
الثورة لصالحه. ومن هنا خرج عنف القوميين الألمان المعادي للبرلمانية.

\section{r. نمو الأزمات المتصادية}

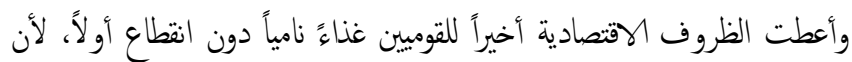

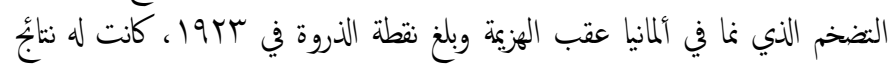

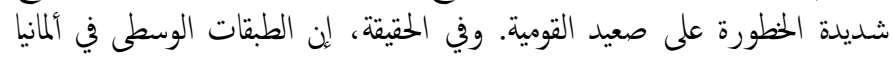

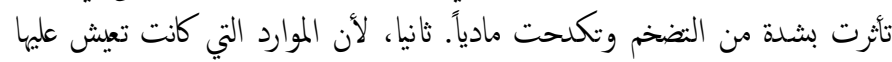

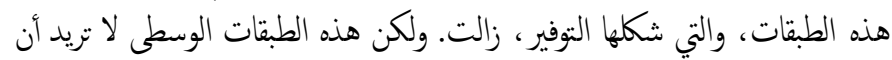

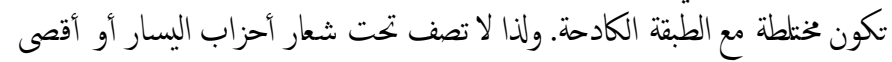

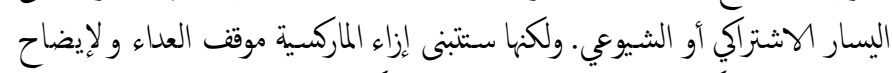

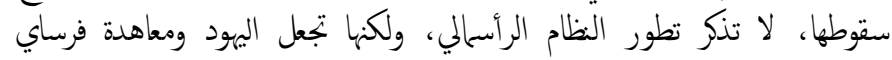

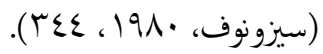

\section{V. القومية العنصرية في ألمايا (919 (19Mr-19)}

\section{تثميز هذه الفترة من بروز الروح القومية العنصرية بثلاث أدوار هي: داثي}

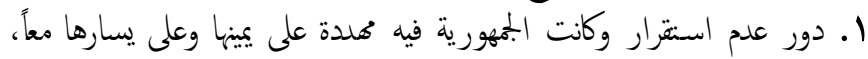

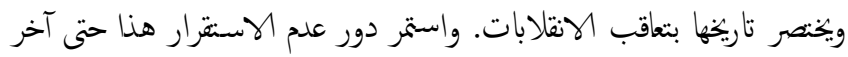

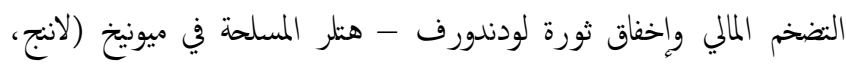

(or ، 1991

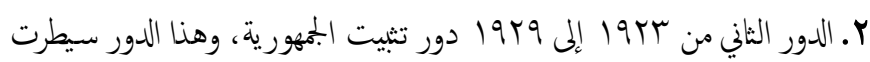

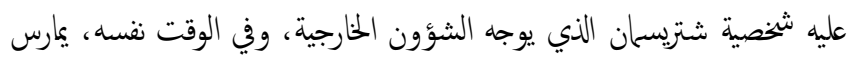

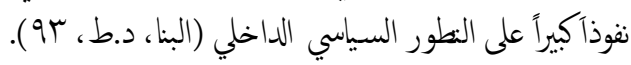

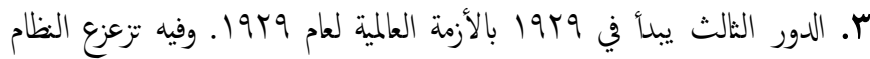

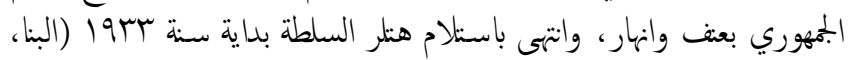

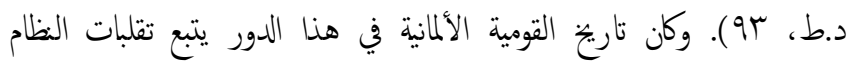
وقد بلغت القومية ذروتها في سيق الدور الأول والثاني فيا كانت بين بrارجا

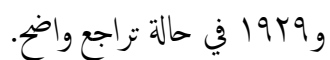

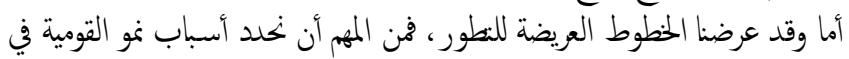

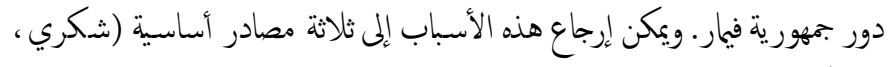

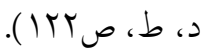

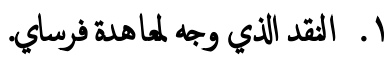

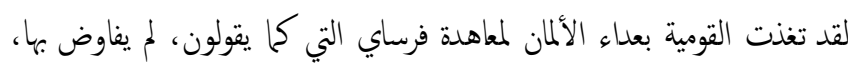

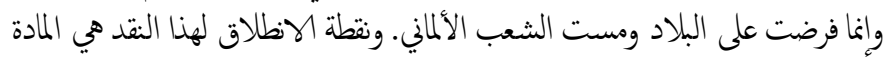

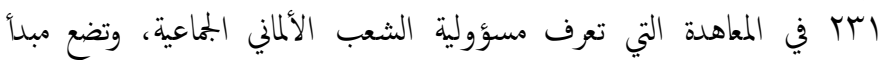

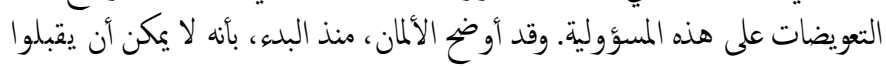

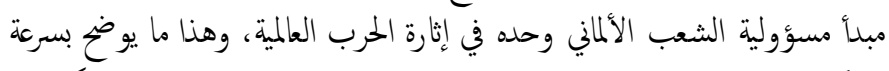

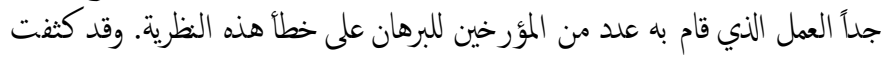

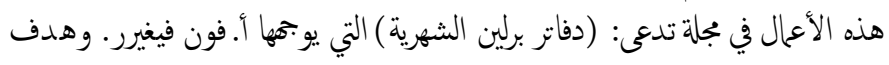

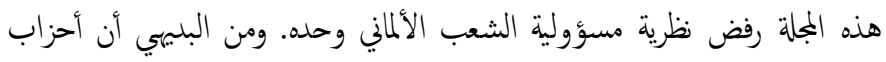

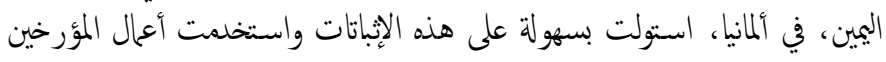

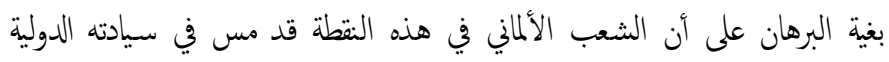

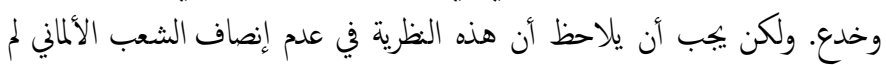

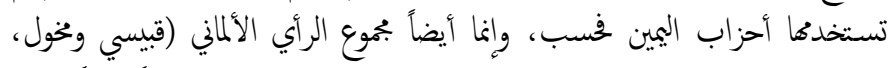

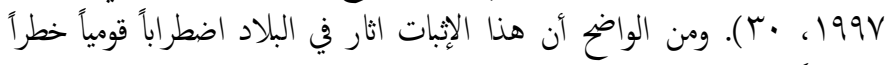

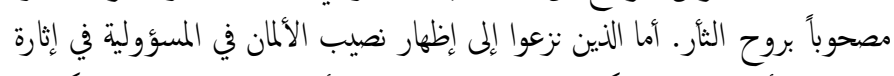

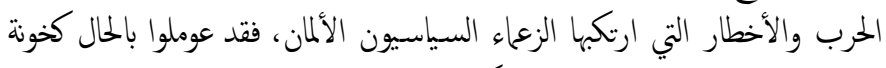

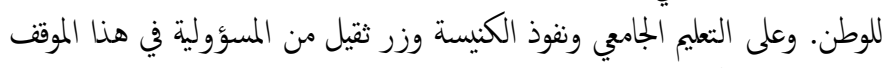

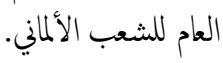

وقد تعلق بهذه الثورة على المادة ابس في المعاهدة، الاحتجاج على الأراضي التي

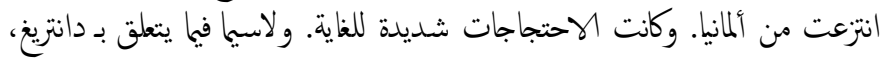

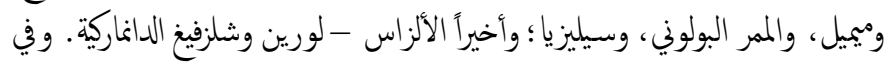


بلا للحكومة أن يدها مكفوفة أمام الرأي العام. اتخذت عدة إجراءات تهدف إلى دحر

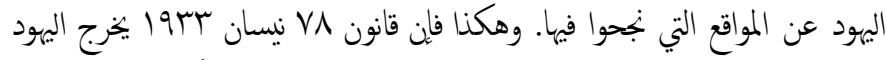

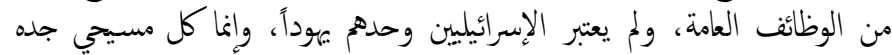

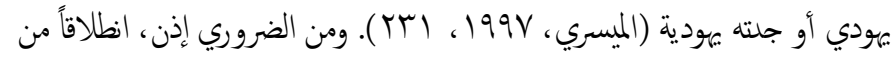

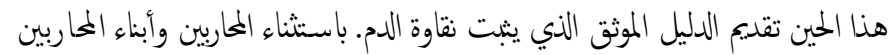

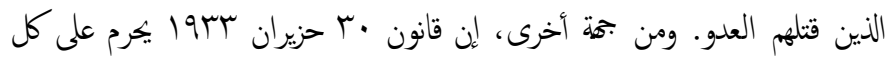

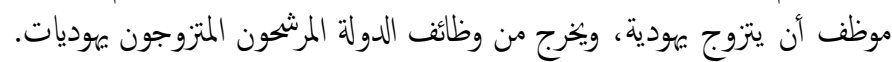

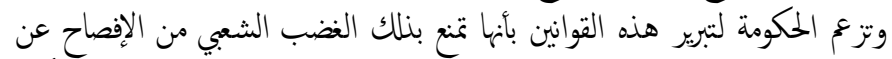

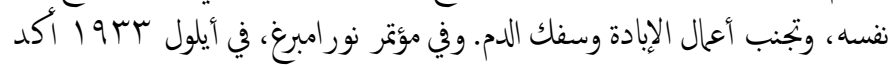

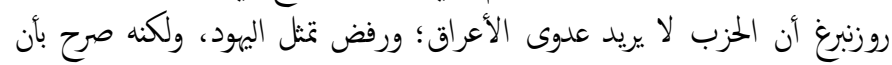

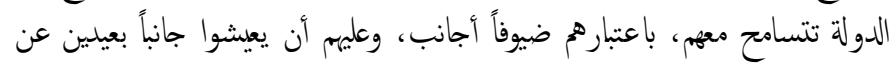

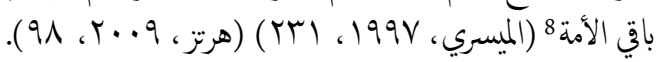

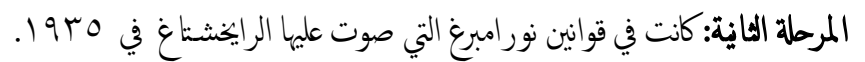

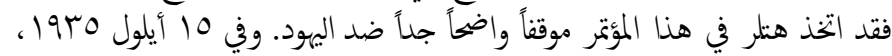

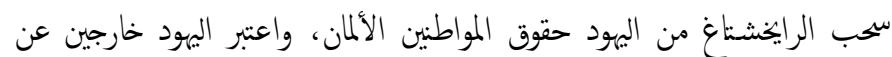

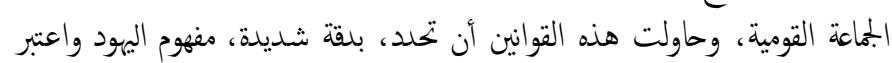

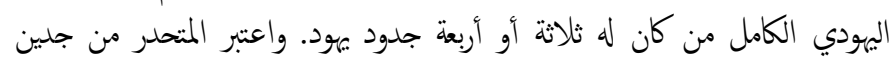

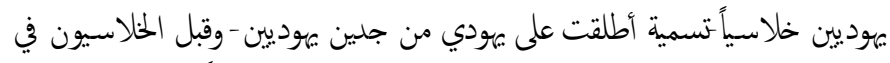

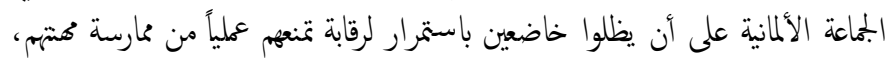

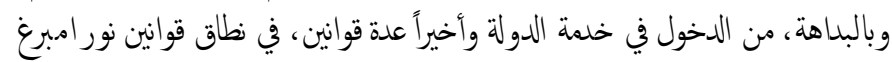

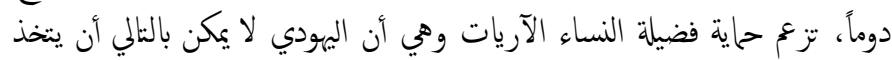

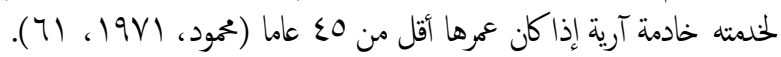

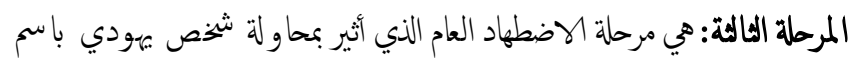

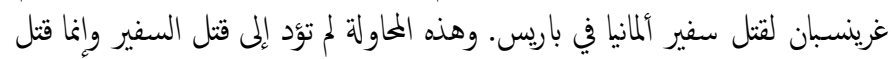

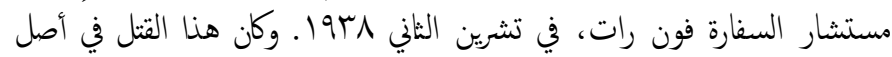

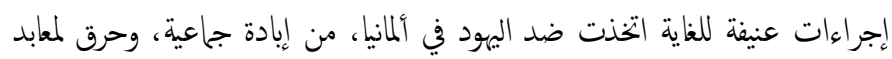

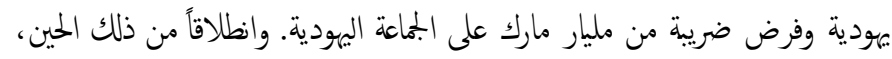

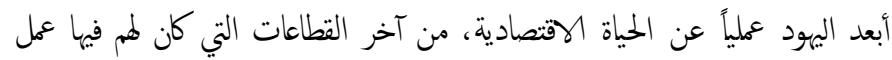

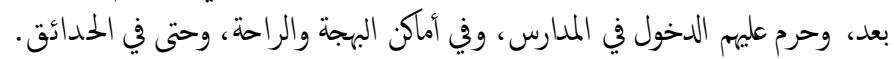

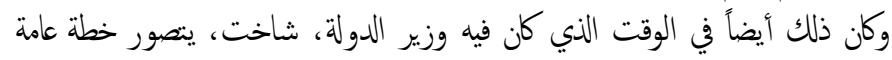

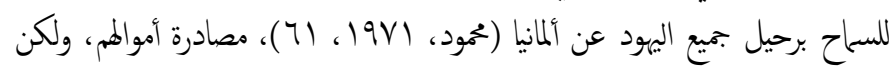

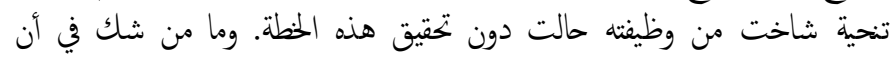

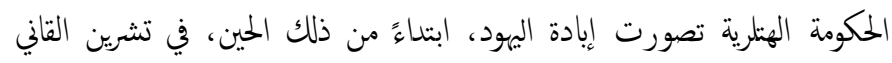

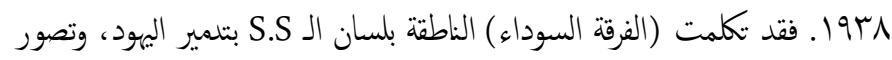

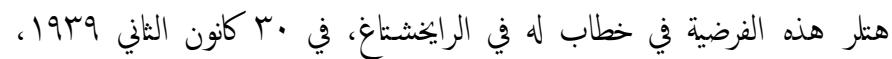

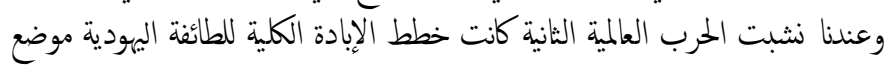

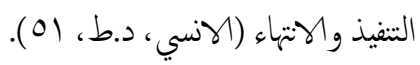

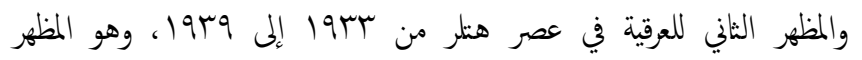

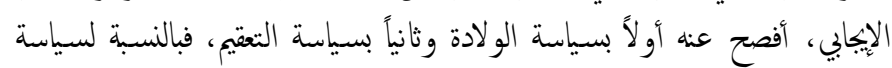

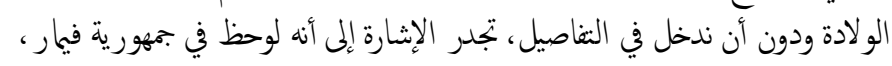

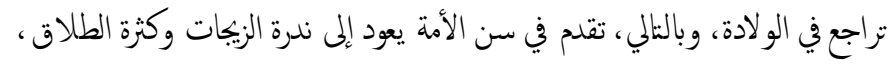

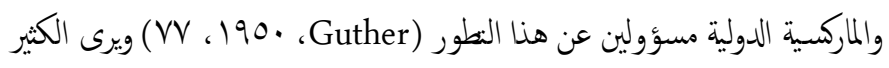

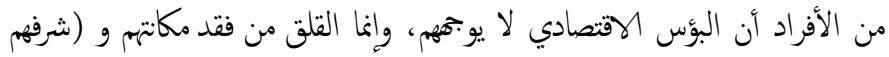

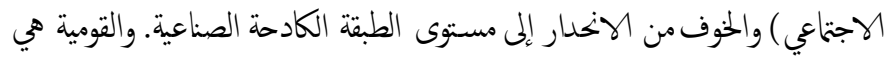

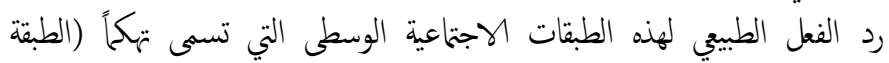

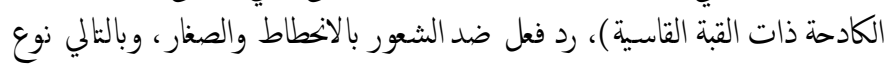

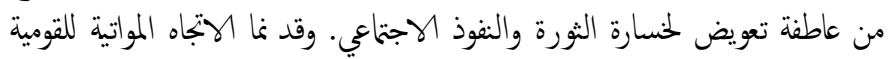

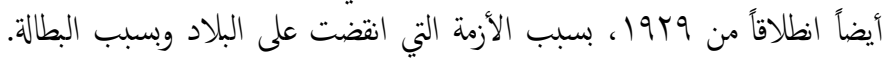

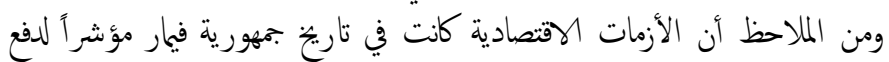

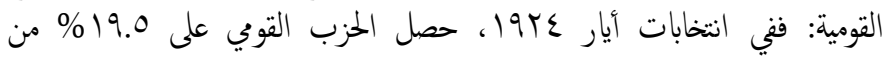

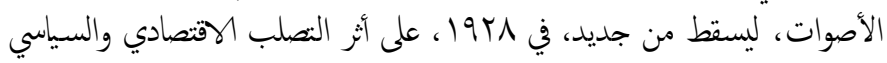

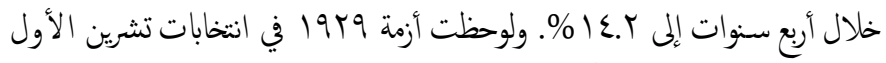

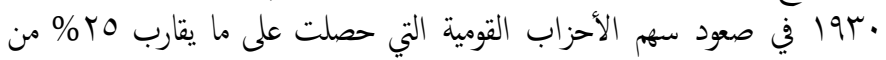

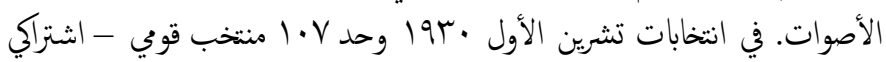

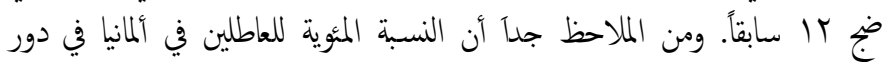

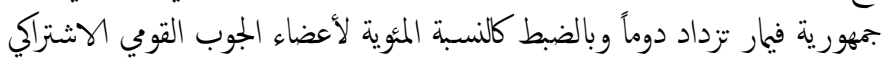

(YYlGrouyet)

\section{1. الاتجاهات القومية في ألمانيا الهتلرية:}

ان العناصر الأساسية للقومية الألمانية في السنوات الأولى للدكثاتورية الهتلرية

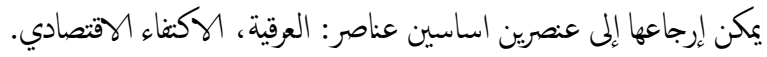

1.1 المرقية:

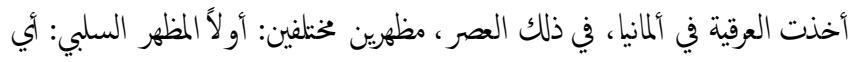

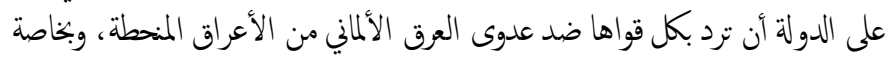

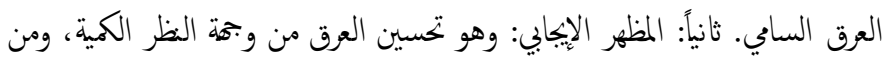

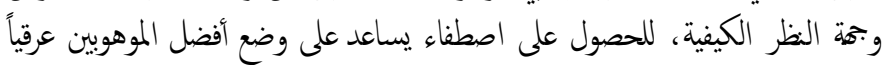

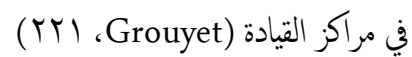

ا ـ المظهر السلبي وهو العداء اللسامية:

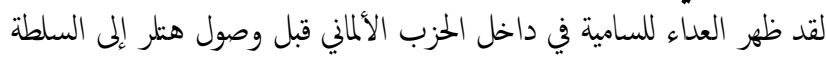

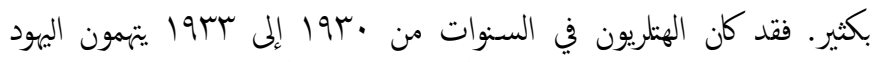

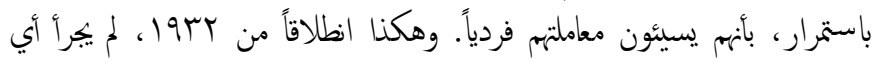

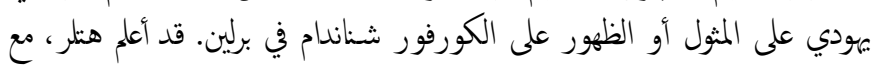

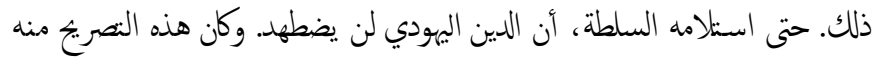

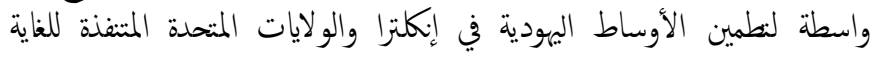

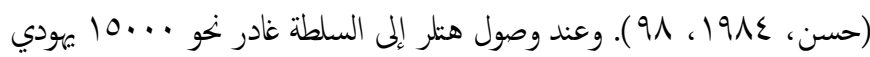

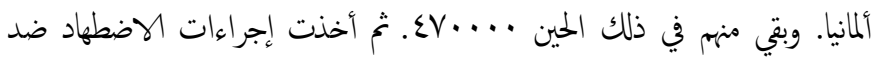

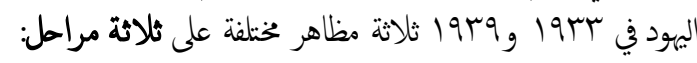

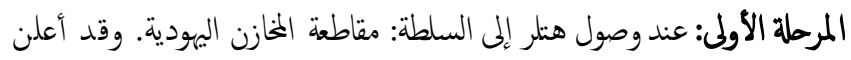

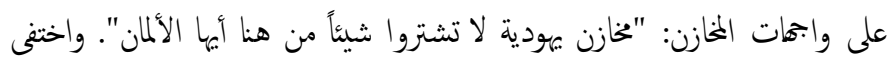

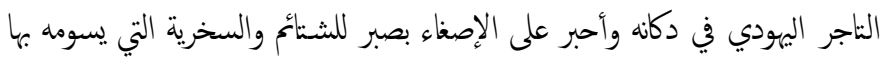

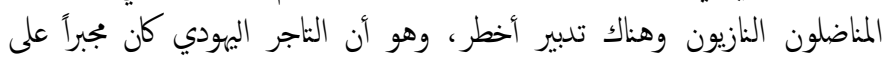

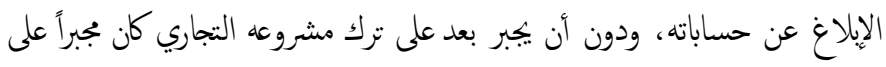

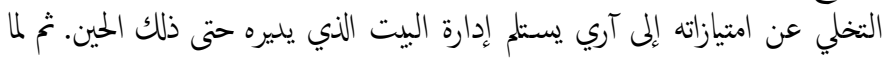




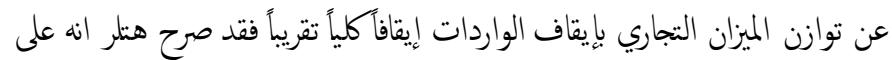

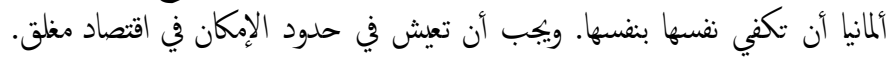

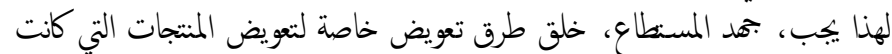

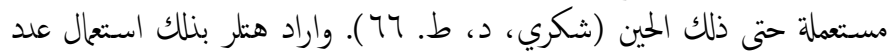

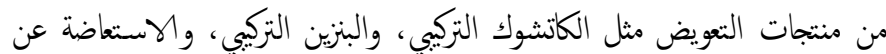

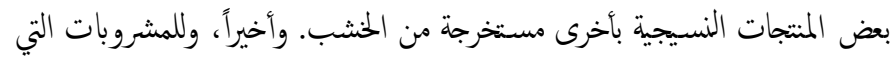

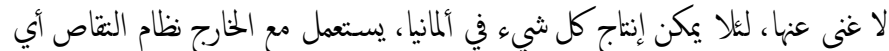

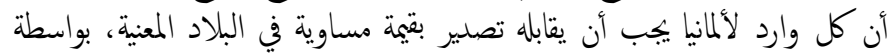

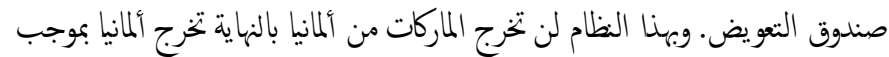
هذه السياسة الاكنفائية، من المبادلات الاقتصادية الدولية 10.

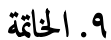

ان الظروف التي احاطت بألمانيا وادت المى ولادة الفكر القومي المنطرف لم تكن

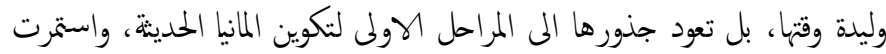

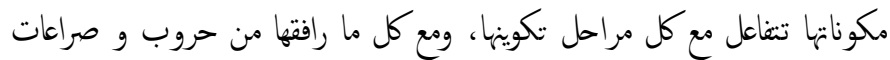

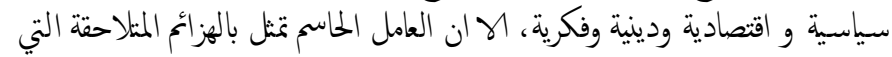

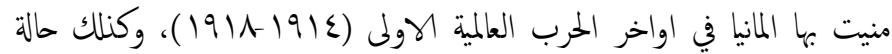

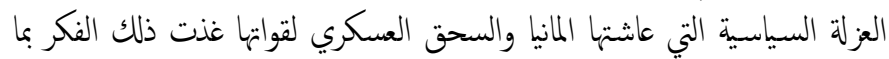
يكني ان ينشا جيلا يقوم بانقلاب جميع موازين القوة لصالح المانيا.

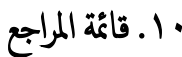

الأدهي، محمد مظفر ، (1911)، تاريخ أوروبا في القرن التاسع عشر، بغداد.

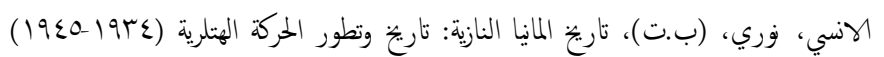

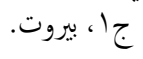

بافلينكو، اناتولي (عو199)، الثورات في العالم المعاصر، ترجة: دار الشرق العربي، طا،

$$
\text { بيروت. }
$$

برينر، ليني، (1910)، الصهيونة في زمن الديكناتورية (النازية، الفاشية، الشيوعية)، ترجمة:

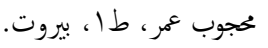

تسن، فرغلي على، (Y . . (Y)، تاريخ أوروبا الحديث والمعاصر، الإسكندرية. جال البنا، ظهور وسقوط جمهورية فيمار: مأساة التخبط في اتخاذ المواقق، القاهرة، د.ت.

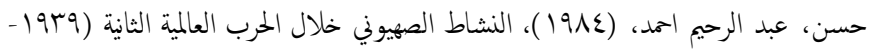

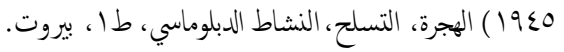

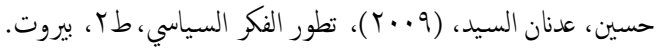
خليل، بطري، (ع +. r)، الفكر القومي وقضايا التجدد الحضاري، القاهرة. د.م، (1971)، الايدولوجية الاملنية (مصادر الاشتراكية العلمية) كارل ماركس فريدريك انجلز ،

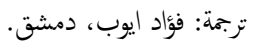

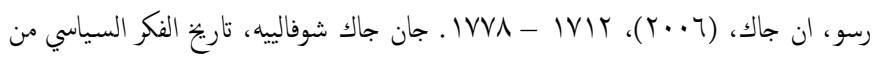

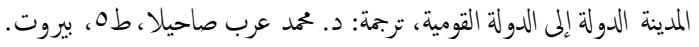

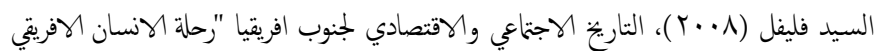

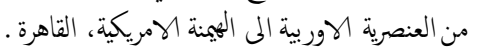

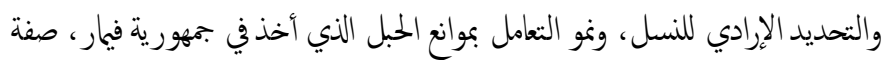

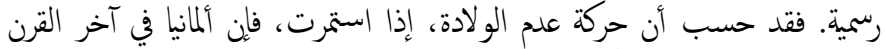

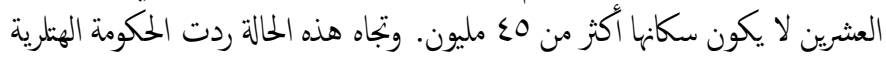

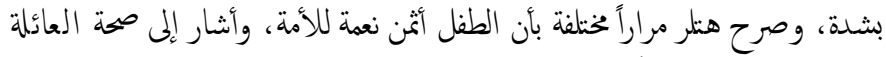

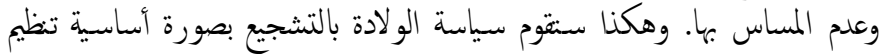

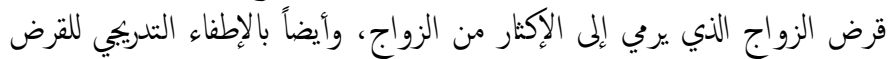

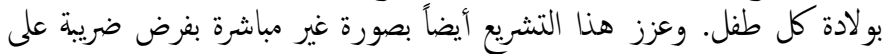

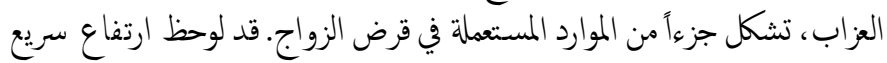

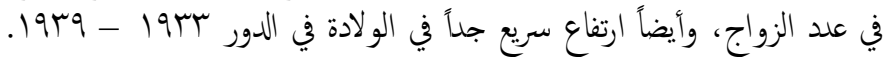

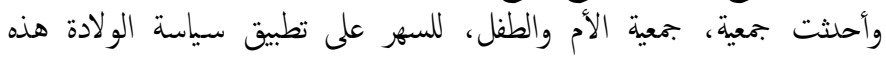
(F.R.1937,VOL.11. (862.00pr/221) PP.331-323)

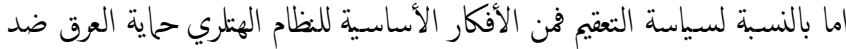

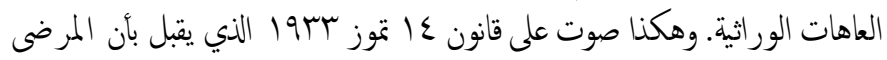

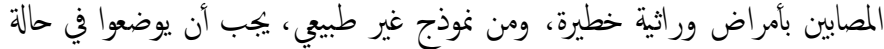

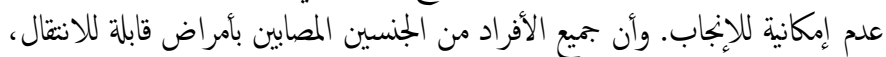

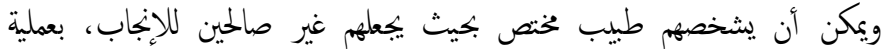

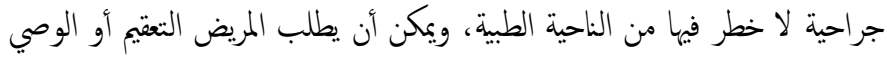

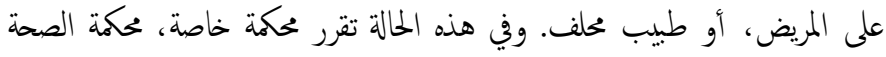

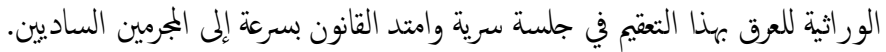

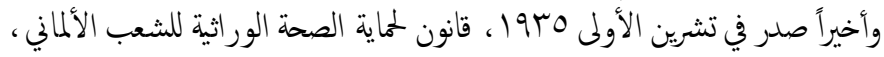

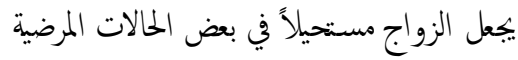
.(F.R.1937,VOL.11. (862.00pr/221) PP.331-323) والحجج التي قدما النازيون لماية هذا التشريع اثنان:

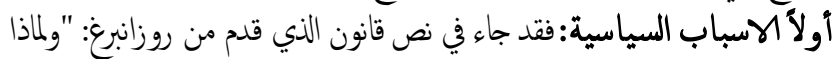

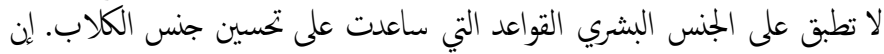

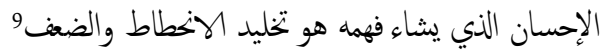

.(F.R.1937,VOL.11. (862.00pr/221) PP.331)-323 ثانيا الاسباب الاقتصادية: حفسب احصائية الامانية بينت ان المجنون يكلف المان

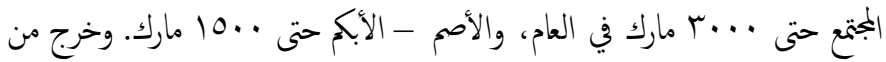

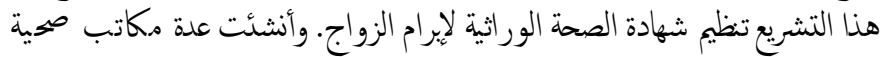

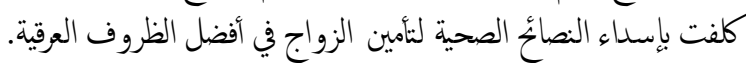
r. باسة الاكتفاء الاقتصادي.

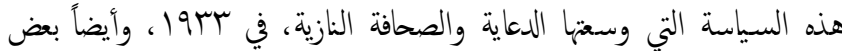

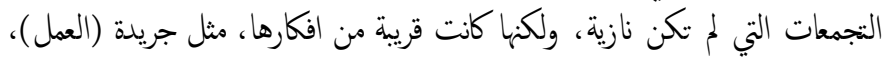

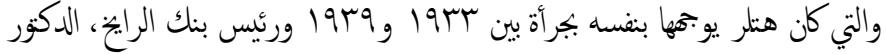

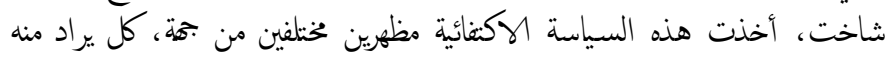

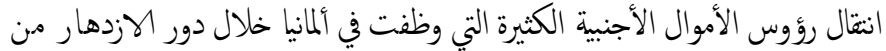

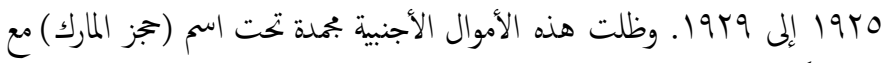

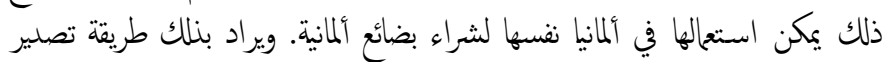

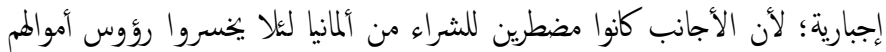

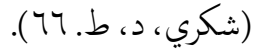
ومن جهة أخرى، كان المظهر الآخر ، لهذه السياسة الاقتصادية الاكنفائية، البحث 


$$
\begin{aligned}
& \text { موريس كروزية، تاريخ الحضارات العام، المعهد المعاصر، المجلد السابع. }
\end{aligned}
$$

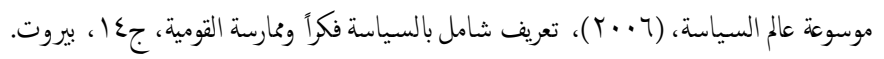

$$
\begin{aligned}
& \text { الميسري، عبد الوهاب، (199V)، الصهيونية والنازية ونهاية التاريخ: رؤية حضارية جديدة، طا، }
\end{aligned}
$$

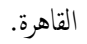

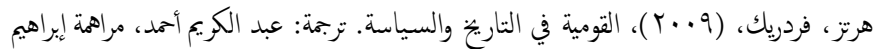

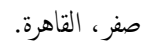

David Thomson ،(1995) ،World History from 1914-1950،Oxford،London.

Edward w. Bennett ،(1962) ،Germany and Diplomacy of the Financial Crisis, 1931 ،Cambridge.

Gordon A. Craig،Germany: 1866-1945،Oxford.P.32.

Grouyet ،Le Monde،Historie fenerale and Civiliasations. F.R.1937،VOL.11. (862.00pr/221)

John Gunther (1950) ،Inside Europe،New York, Microhistory and World Timeline،home/18-19thcenurises ،RUSSIA1856-1900

7 فيما يتصل بالظروف السابقة في جنوب أفريقيا.وفيم يتصل بجزر الهند الهولندية ينظر .... (السيد فليفل ،

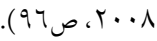

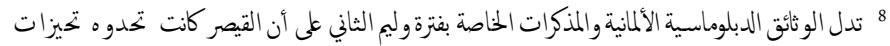

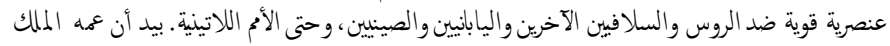

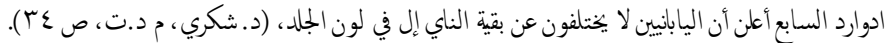

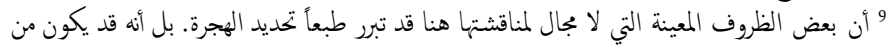

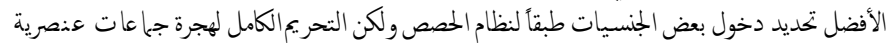

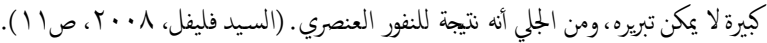

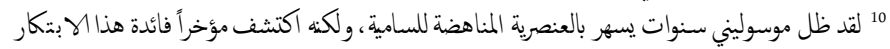

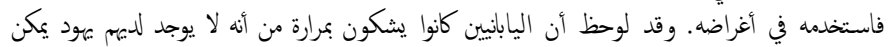

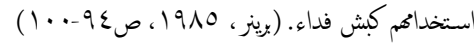

$$
\begin{aligned}
& \text { سيرزونفف، (·191)، تاريخ القرن العشرين، ترجمة: د. نور الدين حاطوم، بيروت. }
\end{aligned}
$$

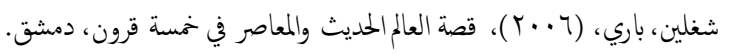

$$
\begin{aligned}
& \text { شكري، عادل محم، (د.ت)، النازية بين الايدولوجية والتطبيق. }
\end{aligned}
$$

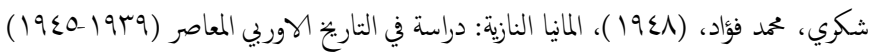

$$
\begin{aligned}
& \text { القاهرة. }
\end{aligned}
$$

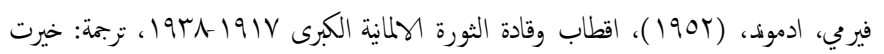

$$
\begin{aligned}
& \text { قبيسي، بشري ومخول، موسى، (199V)، الحروب والازمات الاقليمة في القرن العشرين }
\end{aligned}
$$

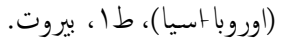

$$
\begin{aligned}
& \text { كابزي، بول، (ع 1999)، نشوءوسقوط الدول العظمى، ترجة: مالك البربري،طا، عمان. }
\end{aligned}
$$

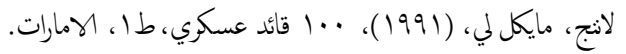

$$
\begin{aligned}
& \text { مجموعة مؤلفين، (1919 )، قاموس المعجم الوسيط في اللغة العربية، اسطنبول. } \\
& \text { محمد صالح، محد و، عبد الكريم ياسين والسامرائي، نوري، (1910)، تاريخ أوروبا في القرن } \\
& \text { التاسع عشر، بغداد. } \\
& \text { محمود، معين احمد، (19VI )، الصهيونية والنازية، طا، القاهرة. }
\end{aligned}
$$

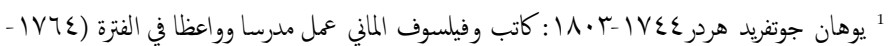

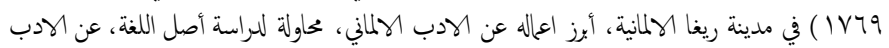

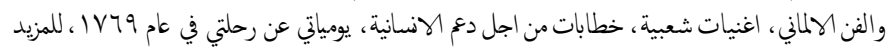

ينظر (Edward.w. Bennett, 1962, 19) 2 الشوفينية: تعرف الشوفينية بانها عبارة عن افراط في الوطنية ينتهي الى معاداة جميع الثقافات والنول

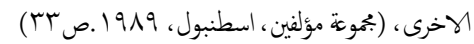

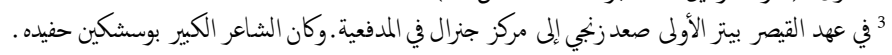

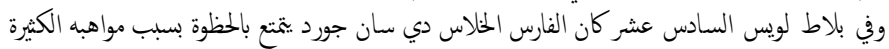

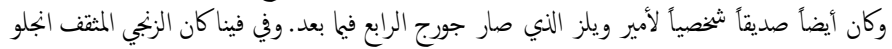

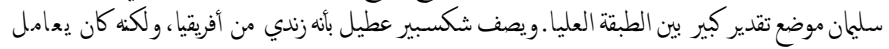

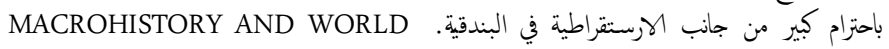
.P55،RUSSIA1856-1900، home/18-19thcenurises ، TIMELINE

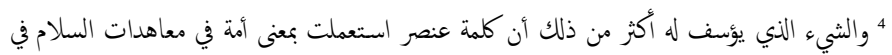

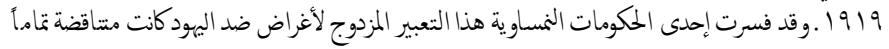

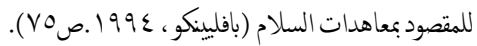

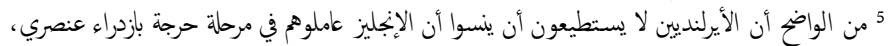

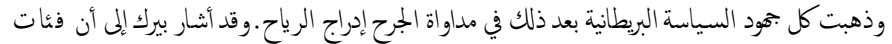

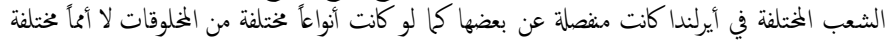

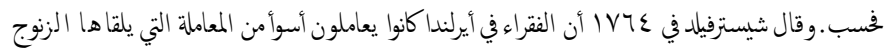

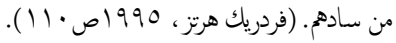

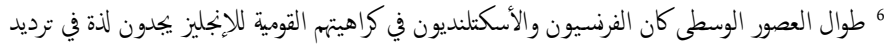

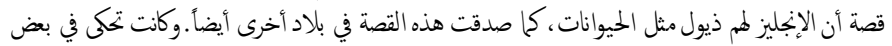

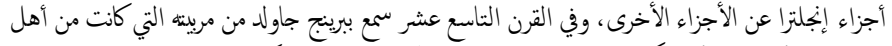

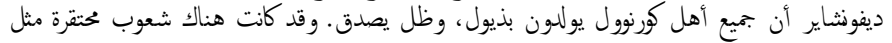

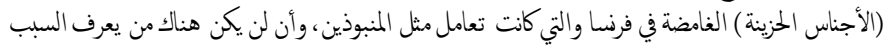

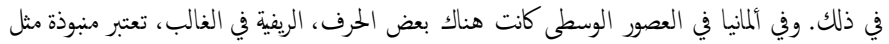

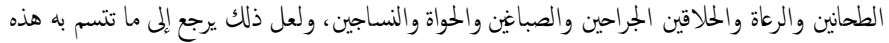

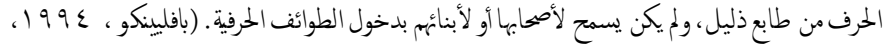

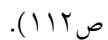

